\title{
Evidências sobre prevenção de lesões de pele em recém-nascidos: revisão integrativa
}

Evidence on prevention of skin lesions in newborns: integrative review

Evidencia sobre prevención de lesiones cutáneas en recién nacidos: revisión integradora

Simone Vidal Santos*, Flávia Regina Souza Ramos², Roberta Costa², Luís Manuel da Cunha Batalha ${ }^{3}$

ORCID IDS

Santos SV (iD https://orcid.org/0000-0002-5086-6326

Ramos FRS (D) https://orcid.org/0000-0002-0077-2292

Costa R (iD https://orcid.org/0000-0001-6816-2047

Batalha LMC (D) https://orcid.org/0000-0002-5328-1470

\section{COMO CITAR}

Santos SV; Ramos FRS; Costa R; Batalha LMC (2019) Evidências sobre prevenção de lesões de pele em recém-nascidos: revisão integrativa. ESTIMA, Braz. J. Enterostomal Ther., 17: e2219. https://doi. org/10.30886/estima.v17.787_PT

Extraído da tese de doutorado intitulada: Neonatal Skin Safe®: Aplicativo móvel de apoio à decisão de enfermeiros na prevenção de lesões de pele em recém-nascidos internados. Programa de Pós-Graduação em Enfermagem, Universidade Federal de Santa Catarina, 2019.

\section{RESUMO}

Objetivo: identificar estratégias para a prevenção de lesões de pele em recém-nascidos (RN) hospitalizados, publicadas em periódicos científicos no período de 2013 a 2018. Método: revisão integrativa de literatura realizada em dois momentos de busca em bases de dados, sendo selecionados 37 estudos publicados entre os anos de 2013 e 2018. Resultados: termorregulação, uso de antisséptico, uso de emolientes e limpeza do coto umbilical foram as recomendações mais encontradas. Entre as práticas baseadas em evidência, destacam-se as que previnem o risco de hipotermia, como o uso de saco de polietileno e o contato pele a pele, que respaldam a assistência e que garantem segurança no cuidado do paciente neonatal. Conclusão: a prevenção de lesões de pele é um tema relevante, entretanto, existe escassez de evidências robustas para sustentar, com segurança, as práticas de cuidados com o RN. Observa-se ainda que as evidências são insuficientes para englobar o universo do tema, demonstrando que o cuidado com a pele é um tema que demanda investimentos e mais pesquisas.

DESCRITORES: Cuidados de Enfermagem; Pele; Recém-nascido; Estomaterapia; Enfermagem Baseada em Evidências.

\footnotetext{
1 Universidade Federal de Santa Catarina - Hospital Universitário Professor Polydoro Ernani de São Thiago - Florianópolis/SC - Brasil. 2Universidade Federal de Santa Catarina - Programa de Pós-Graduação em Enfermagem - Florianópolis/SC - Brasil.

${ }^{3}$ Escola Superior de Enfermagem de Coimbra - Coimbra - Portugal.
}

Autor correspondente: Simone Vidal Santos, E-mail: simonevidal75@gmail.com

Recebido: Jul. 16, 2019 | Aceito: Out. 23, 2019 
ABSTRACT

Objective: To identify strategies for the prevention of skin lesions in hospitalized newborns (NBs), published in scientific journals from 2013 to 2018. Method: Integrative literature review performed in two moments of database search, selecting 37 studies published between 2013 and 2018. Results: Thermoregulation, use of antiseptic, use of emollients and cleaning of the umbilical stump were the most commonly found recommendations. Among the evidence-based practices, we highlight those that prevent the risk of hypothermia, such as the use of a polyethylene bag and skin-to-skin contact, which support the assistance and ensure safety in the care of the neonatal patient. Conclusion: The prevention of skin lesions is a relevant topic. However, there is a scarcity of robust evidence to safely sustain NB care practices. It is also observed that the evidence is insufficient to encompass the universe of the theme, demonstrating that skin care is a theme that requires investment and more research.

KEYWORDS: Nursing care; Skin; Infant, Newborn; Enterostomal therapy; Evidence-based nursing.

\section{RESUMEN}

Objetivo: Identificar estrategias para al prevención de lesiones cutáneas en recién-nacidos (RN) hospitalizados, publicado en revistas científicas de 2013 a 2018. Método: Revisión integral de la literatura realizada en dos momentos de búsqueda en la base de datos, y se seleccionaron 37 estudios publicados entre 2013 y 2018. Resultados: Termorregulación, el uso de antisépticos, uso de emolientes y limpieza del muñón umbilical fueron las recomendaciones más comunes. Las prácticas baseadas en evidencia incluyen aquellas que previenen el riesgo de hipotermia, como el uso de polietileno y contacto piel con piel, que respaldan la atención y garantizan la atención neonatal segura. Conclusión: La prevención de lesiones cutáneas es un tema relevante, sin embargo, existe un falta de evidencia sólida para apoyar de manera segura las prácticas de cuidado del recién nacido. También se observa que la evidencia es insuficientes para abarcar el universo del tema, lo que demuestra que el cuidado de la piel es un tema que requiere inversiones y más investgación.

DESCRIPTORES: Cuidados de enfermería; Piel; Recién nacido; Estomatoterapia; Enfermaría Baseada en la Evidencia.

\section{INTRODUÇÃO}

Cotidianamente, os profissionais que atuam em unidade neonatal (UN) enfrentam desafios no exercício da sua profissão. A equipe de enfermagem, especificamente, desempenha papel fundamental no cuidado ao recém-nascido (RN). Uma das inquietações dessa equipe está relacionada ao cuidado com a pele, pois atuar como barreira protetora é uma das principais funções desse órgão, contribuindo para a termorregulação, diminuição da perda de água transepidérmica (PAT), impedir absorção de agentes químicos e proteger contra a invasão de microrganismos. Entretanto a pele do RN é fina, frágil, sensível e apresenta barreira epidérmica deficiente, particularidades que, aliadas à necessidade de manuseio, realização de diferentes procedimentos, uso de medicamentos e dispositivos para manutenção da vida, expõe o neonato ao risco de lesões e infecções ${ }^{1,2}$.

O recém-nascido pré-termo (RNPT), ou seja, nascido antes de completar 37 semanas de idade gestacional (IG) e o de baixo peso, que nasce com peso inferior a 2.500 gramas, costumam permanecer por tempo prolongado na UN e estão mais susceptíveis ao desenvolvimento de lesões ${ }^{1}$. Os neonatos podem apresentar lesões mecânicas, químicas, térmicas e infecciosas. As que mais acontecem são as lesões por pressão, fricção, cisalhamento, remoção de adesivos, incontinência, irritantes químicos, extravasamento de drogas e queimaduras ${ }^{3}$.

Estudos realizados no Brasil demonstram que a dermatite de fralda é a lesão mais frequente em $\mathrm{RN}$ internado ${ }^{4,5}$. Outras lesões que merecem destaque são os hematomas, equimoses, flebite e infiltração, causadas por punção e terapia intravenosa ${ }^{4,5}$, bem como as lesões relacionadas ao uso de adesivos, o granuloma umbilical e a lesão nasal associada ao uso de dispositivo de ventilação não invasiva ${ }^{4}$.

As práticas de cuidado com a pele realizadas pela equipe que atua em UN estão relacionadas à avaliação diária; manutenção da regulação térmica; formas de realizar os cuidados de higiene; manuseio delicado; cuidados na realização de procedimentos invasivos; hidratação cutânea; medidas para reduzir PAT; escolha do produto adequado para antissepsia da pele, cuidados na utilização dos dispositivos e remoção de adesivos; prevenção de lesões por pressão, punção, extravasamento e dermatite da área de fraldas ${ }^{6,7}$.

Diante do exposto, torna-se fundamental direcionar a atenção para o cuidado com a pele do neonato. Para proteger o RN, o enfermeiro precisa planejar o cuidado e, para isso, deve buscar subsídios que sustentem sua prática, reduzindo os riscos de iatrogenias e, consequentemente, contribuindo com a segurança e qualidade da assistência. Nesse sentido, surge a prática baseada em evidência $(\mathrm{PBE})$ que busca 
incorporar evidências científicas na prática clínica, a fim de indicar o melhor cuidado e/ou terapêutica para o paciente e que, para a tomada de decisão, considera a experiência do profissional, as necessidades do paciente e os recursos disponíveis ${ }^{8}$. Embora evidências sejam essenciais para basear as práticas assistenciais, autores apontam que o RN é considerado uma população vulnerável para a realização de estudos ${ }^{9}$. Além disso, especificidades fisiopatológicas do $\mathrm{RN}$ em desenvolvimento podem prejudicar o desenho do estudo e causar viés ${ }^{10}$.

A decisão de realizar este estudo se respaldou na necessidade de buscar evidências sobre prevenção de lesões de pele em $\mathrm{RN}$, a fim de respaldar a prática assistencial, contribuindo com a melhoria da qualidade da assistência e com a segurança do paciente neonatal.

\section{OBJETIVO}

Identificar estratégias para a prevenção de lesões de pele em RNs hospitalizados, publicadas em periódicos científicos no período de 2013 a 2018.

\section{MÉTODOS}

Trata-se de uma revisão integrativa da literatura, elaborada a partir da delimitação do tema e da questão norteadora, formulação dos objetivos, definição de critérios de inclusão e exclusão, identificação, seleção, categorização e avaliação dos estudos, interpretação dos resultados e apresentação da síntese do conhecimento ${ }^{11}$. Para formular a questão de pesquisa, foi utilizada a estratégia PICo (P: população; I: fenômeno de Interesse; Co: contexto $)^{12}$. Considerou-se então: P: recém-nascidos; I: prevenção de lesões de pele; e, Co: unidade neonatal. Desta forma, delimitou-se como questão de pesquisa: quais são as estratégias disponíveis na literatura sobre prevenção de lesões de pele em recém-nascidos hospitalizados?

A coleta de dados ocorreu em dois momentos de busca na literatura, primeiramente em julho de 2017 e posteriormente em junho de 2018. Ambas foram realizadas nas bases de dados Cochrane Database of Systematic Reviews, MEDLINE (Base de dados da literatura internacional da área Médica e Biomédica), LILACS (Literatura Latino-Americana e do Caribe em Ciências da Saúde) e BDENF (Base de Dados de
Enfermagem), utilizando-se descritores que estão inseridos no Banco de Descritores em Ciências da Saúde (DeCS), sendo: Recém-Nascido, Recém-Nascido Prematuro, Pele, Unidades de Terapia Intensiva Neonatal e Terapia Intensiva Neonatal. Para o levantamento da amostra, utilizaram-se os operadores booleanos “OR" " " $A N D$ " e os descritores em português, inglês e espanhol.

Como critérios de inclusão para a seleção dos estudos desta revisão integrativa, utilizaram-se artigos publicados entre os anos de 2013 e 2018, em periódicos nacionais e internacionais, com textos escritos em português, inglês e espanhol, que abordassem a prevenção de lesões de pele em RNs hospitalizados. Foram excluídos do estudo: editoriais, teses, dissertações, livros, resumos de congresso, estudos de revisão não sistematizados, artigos que não se enquadravam no recorte temporal ou que não atendessem ao objetivo proposto. Artigos encontrados em mais de uma base de dados foram considerados uma só vez.

O recorte temporal de 2013 a 2018 justifica-se pela necessidade de buscar evidências atualizadas sobre o tema em questão. Optou-se pela inclusão de estudos que abordassem o cuidado com a pele do RN desde a sala de parto até seu período de internação na UN. Não foi realizada uma seleção por nível de evidência. As revisões sistemáticas encontradas durante o procedimento de busca não foram incluídas na apresentação dos resultados, mas foram utilizadas para aprofundar a discussão deste estudo.

O processo de análise iniciou-se com a avaliação do título, seguindo-se com a leitura dos resumos das publicações a fim de verificar se contemplavam a questão de pesquisa e se atendiam aos critérios de inclusão estabelecidos. Após a pré-seleção, realizou-se a leitura dos estudos na íntegra, a fim de evitar viés de seleção. Os textos selecionados que não se encontravam na íntegra foram solicitados aos autores via correio eletrônico ou adquiridos através de compra. Foram respeitados os direitos autorais dos autores dos artigos. A amostra final contou com 37 artigos. A Fig. 1 demonstra como ocorreu o processo de seleção seguindo o PRISMA Flow Diagram ${ }^{13}$.

Para a coleta de informações relevantes ao estudo, foi utilizado um protocolo de revisão de literatura ${ }^{11}$ e elaborado um banco de dados no software Excel com as informações: autor(es), país de origem, ano de publicação, periódico de publicação, base de dados, idioma, amostra, delineamento do estudo, tema principal, nível de evidência e recomendação. Para determinar o nível de evidência, utilizou-se a classificação 


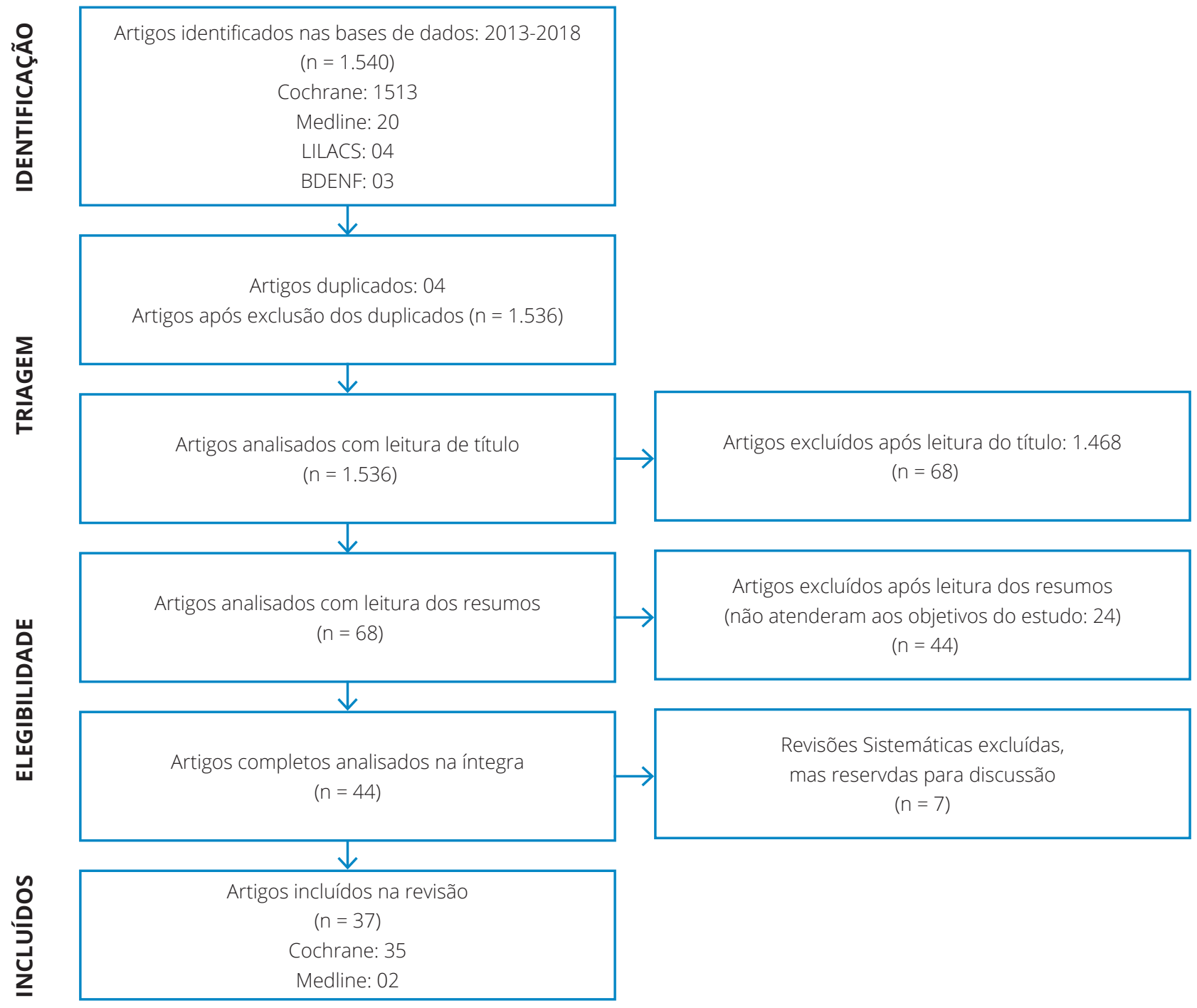

Figura 1. Diagrama do processo de inclusão e exclusão dos estudos, adaptado do modelo PRISMA Flow Diagram ${ }^{13}$.

da Oxford Centrefor Evidence-based Medicine, onde: 1A) revisão sistemática de ensaios clínicos controlados randomizados; 1B) ensaio clínico controlado randomizado (ECCR) com intervalo de confiança estreito; $1 \mathrm{C}$ ) resultados terapêuticos do tipo "tudo ou nada”;2A) revisão sistemática de estudos de coorte; $2 \mathrm{~B}$ ) estudo de coorte e Ensaio Clínico Randomizado (ECR) de menor qualidade; 2C) observação de resultados terapêuticos ou estudos ecológicos; $3 \mathrm{~A}$ ) revisão sistemática de estudos caso-controle; 3B) estudo caso-controle; 4) relato de casos (inclui coorte ou caso-controle de menor qualidade); 5) opinião de especialistas ${ }^{14}$.

A fim de garantir rigor metodológico, evitando viés na seleção e categorização dos estudos por interpretação errônea no delineamento e nos resultados, a pesquisa foi realizada por dois revisores de forma simultânea e independente. A seleção da amostra seguiu o mesmo processo sequencial de leitura: título, resumo e texto na íntegra. Os dados foram agrupados de acordo com temas semelhantes e subdivididos em categorias: termorregulação, uso de emolientes, antisséptico, dispositivos para oxigenação, acesso venoso, limpeza do coto umbilical e cuidados gerais. A síntese e a análise crítica dos resultados serão apresentadas de forma descritiva a seguir.

\section{RESULTADOS}

Dos 37 artigos que compuseram a amostra, todos foram publicados em revistas internacionais. O ECR foi o delineamento mais encontrado, com destaque para o nível de evidência 2B. Dentre os cuidados, destacaram-se: medidas para promover a termorregulação, uso de emolientes, uso de antisséptico tópico, cuidados com o coto umbilical e oxigenação. A síntese dos mesmos está apresentada na Tabela 1. 
Tabela 1. Síntese dos estudos incluídos na revisão.

\begin{tabular}{|c|c|c|c|c|c|}
\hline $\begin{array}{c}\text { Título } \\
\text { (Referência) }\end{array}$ & $\begin{array}{c}\text { Periódico } \\
\text { (Ano) }\end{array}$ & $\begin{array}{l}\text { Amostra/ } \\
\text { Delineam. }\end{array}$ & Intervenção & Resultados & NE \\
\hline $\begin{array}{l}\text { Randomized controlled } \\
\text { trial of vinyl bags versus } \\
\text { thermal mattress to } \\
\text { prevent hypothermia in } \\
\text { extremely } \\
\text { low-gestational-age } \\
\text { infants }\end{array}$ & $\begin{array}{l}\text { Am. J. Perinatol. } \\
\text { (2013) }\end{array}$ & $41 \mathrm{RN}$; ECCR. & $\begin{array}{l}\text { Saco de vinil versus } \\
\text { colchões de aquecimento } \\
\text { na prevenção de } \\
\text { hipotermia. }\end{array}$ & $\begin{array}{l}\text { Sacos de vinil e colchão de } \\
\text { aquecimento são igualmente eficazes } \\
\text { na melhoria da temperatura de } \\
\text { admissão. Melhorias em outras áreas, } \\
\text { como a temperatura da sala de parto, } \\
\text { podem ser necessárias para atingir o } \\
\text { objetivo de prevenir hipotermia nessa } \\
\text { população vulnerável. }\end{array}$ & $2 \mathrm{~B}$ \\
\hline $\begin{array}{l}\text { A randomized controlled } \\
\text { trial of plastic drape } \\
\text { for prevention of } \\
\text { hypothermia during } \\
\text { umbilical } \\
\text { catheterization }^{16}\end{array}$ & $\begin{array}{l}\text { Am. J. Perinatol. } \\
\text { (2013) }\end{array}$ & $60 \mathrm{RN} ; \mathrm{ECCR}$ & $\begin{array}{l}\text { Saco de polietileno na } \\
\text { prevenção de hipotermia } \\
\text { durante procedimento. }\end{array}$ & $\begin{array}{l}\text { A cobertura plástica de polietileno } \\
\text { foi superior ao campo convencional } \\
\text { na manutenção da temperatura } \\
\text { retal e na prevenção de hipotermia } \\
\text { durante o cateterismo umbilical. }\end{array}$ & $2 \mathrm{~B}$ \\
\hline $\begin{array}{l}\text { A randomized trial of } \\
\text { exothermic mattresses } \\
\text { for preterm newborns in } \\
\text { polyethylene bags }{ }^{17}\end{array}$ & $\begin{array}{c}\text { Pediatrics } \\
\text { (2013) }\end{array}$ & 72 RN; ECCR. & $\begin{array}{l}\text { Saco de polietileno } \\
\text { associado à matriz } \\
\text { exotérmica na } \\
\text { temperatura do RNPT. }\end{array}$ & $\begin{array}{l}\text { O uso de matriz exotérmica } \\
\text { associada ao saco de polietileno, } \\
\text { em RNPT resultou em mais crianças } \\
\text { com temperaturas fora do intervalo } \\
\text { normal e mais hipertermia na } \\
\text { admissão na UN. }\end{array}$ & $2 \mathrm{~B}$ \\
\hline $\begin{array}{l}\text { Plastic bags for prevention } \\
\text { of hypothermia in } \\
\text { preterm and low birth } \\
\text { weight infants }{ }^{18}\end{array}$ & $\begin{array}{c}\text { Pediatrics } \\
\text { (2013) }\end{array}$ & $\begin{array}{l}104 \mathrm{RN} ; \\
\text { ECCR. }\end{array}$ & $\begin{array}{l}\text { Bolsa plástica ao nascer } \\
\text { mantém a normotermia } \\
\text { do RNPT e RN de baixo } \\
\text { peso. }\end{array}$ & $\begin{array}{l}\text { O uso de uma bolsa plástica no } \\
\text { nascimento em comparação com os } \\
\text { cuidados padrão de termorregulação } \\
\text { reduziu a hipotermia sem resultar em } \\
\text { hipertermia e é uma ferramenta de } \\
\text { baixa tecnologia e baixo custo para } \\
\text { locais onde os recursos são limitados. }\end{array}$ & $2 \mathrm{~B}$ \\
\hline $\begin{array}{l}\text { Randomized trial } \\
\text { of plastic bags to } \\
\text { prevent term neonatal } \\
\text { hypothermia in a } \\
\text { resource-poor setting }\end{array}$ & $\begin{array}{c}\text { Pediatrics } \\
\text { (2013) }\end{array}$ & $\begin{array}{c}271 \mathrm{RN} \\
\text { ECCR. }\end{array}$ & $\begin{array}{l}\text { RN a termo em sacos } \\
\text { plásticos reduz a } \\
\text { hipotermia em } 1 \text { hora } \\
\text { após o nascimento. }\end{array}$ & $\begin{array}{l}\text { Colocação de saco plástico no } \\
\text { nascimento reduziu a incidência } \\
\text { de hipotermia em } 1 \text { hora após } \\
\text { o nascimento em RNs a termo } \\
\text { nascidos em um cenário de } \\
\text { recursos pobres, mas a maioria dos } \\
\text { neonatos permaneceu hipotérmica. }\end{array}$ & $2 B$ \\
\hline $\begin{array}{l}\text { Effect of early skin-to-skin } \\
\text { contact following normal } \\
\text { delivery on incidence of } \\
\text { hypothermia in neonates } \\
\text { more than } 1800 \mathrm{~g} \text { : } \\
\text { randomized control trial2o }\end{array}$ & $\begin{array}{l}\text { J. Perinatol. } \\
\text { (2014) }\end{array}$ & $\begin{array}{l}100 \mathrm{RN} \\
\text { ECCR. }\end{array}$ & $\begin{array}{l}\text { Contato pele a pele } \\
\text { precoce na incidência de } \\
\text { hipotermia em RNs de } \\
\text { baixo peso. }\end{array}$ & $\begin{array}{l}\text { alcançaram rápido controle térmico } \\
\text { em comparação com o grupo } \\
\text { controle. O contato pele a pele } \\
\text { precoce por } 24 \text { h após o nascimento } \\
\text { diminui a incidência de hipotermia } \\
\text { nas primeiras } 48 \text { h de vida e precisa } \\
\text { ser agressivamente promovido em } \\
\text { RNs a termo e RNPTs para reduzir a } \\
\text { incidência de hipotermia. }\end{array}$ & $2 B$ \\
\hline $\begin{array}{l}\text { Heat loss prevention } \\
\text { (help) after birth in } \\
\text { preterm infants using } \\
\text { vinyl isolation bag or } \\
\text { polyethylene wrap }\end{array}$ & $\begin{array}{l}\text { JOGN Nurs. } \\
\text { (2014) }\end{array}$ & $59 \mathrm{RN}$; ECCR. & $\begin{array}{l}\text { Saco de vinil ou de } \\
\text { polietileno para prevenir } \\
\text { hipotermia em RNPTs. }\end{array}$ & $\begin{array}{l}\text { Envolver RNPTS com idade } \\
\text { gestacional } \leq 32 \text { semanas em bolsas } \\
\text { de vinil imediatamente após o } \\
\text { nascimento está associado a menor } \\
\text { incidência de hipotermia. }\end{array}$ & $2 B$ \\
\hline $\begin{array}{l}\text { Total body polyethylene } \\
\text { wraps for preventing } \\
\text { hypothermia in preterm } \\
\text { infants: a randomized tria }{ }^{22}\end{array}$ & $\begin{array}{c}\text { J. Pediatr. } \\
\text { (2014) }\end{array}$ & $\begin{array}{l}100 \mathrm{RN} \\
\text { ECCR. }\end{array}$ & $\begin{array}{l}\text { Saco de polietileno (corpo } \\
\text { e cabeça) ou (até ombros) } \\
\text { termorregulação de } \\
\text { RNPTs. }\end{array}$ & $\begin{array}{l}\text { comparável com a cobertura do } \\
\text { corpo até os ombros na prevenção } \\
\text { de perdas térmicas pós-natais em } \\
\text { RNPTs. }\end{array}$ & 1B \\
\hline
\end{tabular}


Tabela 1. Continuação...

\begin{tabular}{|c|c|c|c|c|c|}
\hline $\begin{array}{c}\text { Título } \\
\text { (Referência) }\end{array}$ & $\begin{array}{c}\text { Periódico } \\
\text { (Ano) }\end{array}$ & $\begin{array}{l}\text { Amostra/ } \\
\text { Delineam. }\end{array}$ & Intervenção & Resultados & NE \\
\hline $\begin{array}{l}\text { Thermal Blanket to Improve } \\
\text { Thermoregulation in Preterm } \\
\text { Infants: a Randomized } \\
\text { Controlled Triap3 }\end{array}$ & $\begin{array}{l}\text { Pediatr. Crit. } \\
\text { Care Med. } \\
\text { (2015) }\end{array}$ & $80 \mathrm{RN} ; \mathrm{ECCR}$ & $\begin{array}{l}\text { Manta térmica e berço } \\
\text { radiante na termorregulação } \\
\text { e na pressão arterial de RNs } \\
\text { de baixo peso. }\end{array}$ & $\begin{array}{l}\text { O uso de manta térmica melhorou } \\
\text { a hipotermia, o que se relacionou } \\
\text { com menos casos de hipotensão e } \\
\text { menos uso de dopamina. }\end{array}$ & $2 \mathrm{~B}$ \\
\hline $\begin{array}{l}\text { Randomized trial of } \\
\text { occlusive wrap for heat } \\
\text { loss prevention in preterm } \\
\text { infants }{ }^{24}\end{array}$ & $\begin{array}{l}\text { J. Pediatr. } \\
\text { (2015) }\end{array}$ & $\begin{array}{l}801 \mathrm{RN} \\
\text { ECCR. }\end{array}$ & $\begin{array}{l}\text { Envoltório oclusivo ao } \\
\text { nascimento reduz a } \\
\text { mortalidade de RNPT. }\end{array}$ & $\begin{array}{l}\text { A aplicação de envoltório oclusivo } \\
\text { em RNPT, imediatamente após } \\
\text { o nascimento, resulta em maior } \\
\text { temperatura corporal média, mas } \\
\text { não reduz a mortalidade. }\end{array}$ & $1 \mathrm{~B}$ \\
\hline $\begin{array}{l}\text { Weight at weaning of } \\
\text { preterm infants from } \\
\text { incubator to bassinet: a } \\
\text { randomized clinical trial25 }\end{array}$ & $\begin{array}{l}\text { Am. J. Perinatol. } \\
\text { (2014) }\end{array}$ & $21 \mathrm{RN}$; ECCR. & $\begin{array}{l}\text { Resposta térmica de RNs } \\
\text { retirados da incubadora } \\
\text { com } 1.500 \text { ou } 1.600 \mathrm{~g} \text {. }\end{array}$ & $\begin{array}{l}\text { O desmame de RNs de muito baixo } \\
\text { peso ( } 1.500 \text { g) de uma incubadora } \\
\text { a um berço de aquecimento é } \\
\text { factível e não tem efeitos deletérios } \\
\text { significativos sobre o ganho de peso. }\end{array}$ & $2 B$ \\
\hline $\begin{array}{l}\text { Keeping babies warm: } \\
\text { a non-inferiority trial of } \\
\text { a conductive thermal } \\
\text { mattress }^{26}\end{array}$ & $\begin{array}{l}\text { Arch. Dis. Child. } \\
\text { Fetal Neonatal } \\
\text { Ed. (2015) }\end{array}$ & $\begin{array}{l}160 \mathrm{RN} \\
\text { ECCR. }\end{array}$ & $\begin{array}{l}\text { Colchão térmico condutor } \\
\text { ou cuidado padrão para } \\
\text { aquecimento: RN de baixo } \\
\text { peso. }\end{array}$ & $\begin{array}{l}\text { O uso de curta duração de colchão } \\
\text { térmico condutor em comparação } \\
\text { com aquecedores radiantes e outros } \\
\text { modos de aquecimento não é inferior } \\
\text { ao cuidado padrão, sendo eficaz } \\
\text { na manutenção da temperatura } \\
\text { corporal, sem efeito adverso. }\end{array}$ & $2 B$ \\
\hline $\begin{array}{l}\text { Polyethylene versus cotton } \\
\text { cap as an adjunct to body } \\
\text { wrap in preterm infants }{ }^{27}\end{array}$ & $\begin{array}{l}\text { Pediatr. Int. } \\
\text { (2017) }\end{array}$ & $80 \mathrm{RN}$; ECCR. & $\begin{array}{l}\text { Touca de polietileno } \\
\text { ou algodão associada } \\
\text { ao saco de polietileno: } \\
\text { termorregulação. }\end{array}$ & $\begin{array}{l}\text { O uso combinado de envoltório } \\
\text { de polietileno no corpo e touca } \\
\text { de polietileno foi associado a uma } \\
\text { temperatura pós-estabilização } \\
\text { média significativamente maior em } \\
\text { comparação com envoltório de } \\
\text { polietileno no corpo e touca de algodão. }\end{array}$ & $2 B$ \\
\hline $\begin{array}{l}\text { Using polyethylene plastic } \\
\text { bag to prevent moderate } \\
\text { hypothermia during } \\
\text { transport in very low } \\
\text { birth weight infants: a } \\
\text { randomized trial28 }\end{array}$ & $\begin{array}{c}\text { J. Perinatol. } \\
\text { (2018) }\end{array}$ & $\begin{array}{l}108 \mathrm{RN} \\
\text { ECCR. }\end{array}$ & $\begin{array}{l}\text { RNs de muito baixo } \\
\text { peso em sacos plásticos } \\
\text { durante o transporte } \\
\text { reduz a hipotermia. }\end{array}$ & $\begin{array}{l}\text { A colocação de RNs de muito } \\
\text { baixo peso em sacos plásticos de } \\
\text { polietileno durante o transporte } \\
\text { reduz a ocorrência de hipotermia } \\
\text { moderada. }\end{array}$ & $2 \mathrm{~B}$ \\
\hline $\begin{array}{l}\text { Wrapping newborn } \\
\text { infants in cloth and } \\
\text { newspaper after delivery } \\
\text { led to higher temperatures } \\
\text { on arrival at the neonatal } \\
\text { intensive care unit }{ }^{29}\end{array}$ & $\begin{array}{c}\text { Acta Paediatr. } \\
\text { (2018) }\end{array}$ & $\begin{array}{l}100 \mathrm{RN} \\
\text { ECCR. }\end{array}$ & $\begin{array}{l}\text { Propriedades térmicas } \\
\text { de folhas de jornal entre } \\
\text { lençóis de algodão para } \\
\text { RNs. }\end{array}$ & $\begin{array}{l}\text { Envolver RNs em duas folhas de } \\
\text { tecido com uma camada de jornal } \\
\text { resultou em maior temperatura } \\
\text { corporal na chegada à UTIN e após } \\
\text { uma hora. }\end{array}$ & $2 B$ \\
\hline $\begin{array}{l}\text { Mechanism for } \\
\text { prevention of infection } \\
\text { in preterm neonates } \\
\text { by topical emollients: a } \\
\text { randomized, controlled } \\
\text { clinical triaß }^{30}\end{array}$ & $\begin{array}{l}\text { Pediatr. Infect. } \\
\text { Dis. J. (2014) }\end{array}$ & $\begin{array}{l}491 \mathrm{RN} ; \\
\text { ECCR. }\end{array}$ & $\begin{array}{l}\text { Emoliente no escore de } \\
\text { condição da pele e risco } \\
\text { de infecção sistêmica. }\end{array}$ & $\begin{array}{l}\text { A terapia com emolientes está } \\
\text { associada com ganho de peso } \\
\text { melhorado, risco reduzido de } \\
\text { infecção e mortalidade neonatal } \\
\text { associada em RNPT, sendo uma } \\
\text { intervenção potencialmente } \\
\text { promissora para uso em ambientes } \\
\text { com poucos recursos. }\end{array}$ & $2 B$ \\
\hline $\begin{array}{l}\text { Application of moisturizer } \\
\text { to neonates prevents } \\
\text { development of atopic } \\
\text { dermatitis }^{31}\end{array}$ & $\begin{array}{l}\text { J. allergy clin. } \\
\text { Immunol. } \\
\text { (2014) }\end{array}$ & $\begin{array}{l}118 \mathrm{RN} \\
\text { ECCR. }\end{array}$ & $\begin{array}{l}\text { Hidratante previne } \\
\text { dermatite atópica e } \\
\text { sensibilização alérgica. }\end{array}$ & $\begin{array}{l}\text { A aplicação diária de hidratante durante } \\
\text { as primeiras } 32 \text { semanas de vida reduz } \\
\text { o risco de dermatite atópica/eczema } \\
\text { em lactentes. Sensibilização alérgica } \\
\text { durante esse período está associada } \\
\text { com a presença de pele eczematosa, } \\
\text { não com o uso de hidratante. }\end{array}$ & $2 B$ \\
\hline
\end{tabular}


Tabela 1. Continuação...

\begin{tabular}{|c|c|c|c|c|c|}
\hline $\begin{array}{c}\text { Título } \\
\text { (Referência) }\end{array}$ & $\begin{array}{l}\text { Periódico } \\
\text { (Ano) }\end{array}$ & $\begin{array}{l}\text { Amostra/ } \\
\text { Delineam. }\end{array}$ & Intervenção & Resultados & NE \\
\hline $\begin{array}{l}\text { The effect of topical } \\
\text { ointment on neonatal } \\
\text { sepsis in preterm } \\
\text { infants }\end{array}$ & $\begin{array}{l}\text { J. Matern. Fetal } \\
\text { Neonatal Med. } \\
\text { (2014) }\end{array}$ & $\begin{array}{l}197 \mathrm{RN} \\
\text { ECCR. }\end{array}$ & $\begin{array}{l}\text { Efeitos do uso de pomada } \\
\text { tópica na sepse neonatal. }\end{array}$ & $\begin{array}{l}\text { A aplicação tópica de emoliente } \\
\text { durante as primeiras duas semanas } \\
\text { pós-natais não afetou o risco de } \\
\text { sepse neonatal em RNPT, embora } \\
\text { tenha alterado a flora bacteriana na } \\
\text { pele em comparação com o grupo de } \\
\text { cuidados de rotina. }\end{array}$ & $2 B$ \\
\hline $\begin{array}{l}\text { Influence of sunflower } \\
\text { seed oil on the skin barrier } \\
\text { function of preterm } \\
\text { infants: a randomized } \\
\text { controlled triaß33 }\end{array}$ & $\begin{array}{l}\text { Dermatology } \\
\text { (2014) }\end{array}$ & $22 \mathrm{RN}$; ECCR. & $\begin{array}{l}\text { Óleo de semente } \\
\text { de girassol no } \\
\text { desenvolvimento de } \\
\text { barreira cutânea em RNPT. }\end{array}$ & $\begin{array}{l}\text { A aplicação de óleo de semente de } \\
\text { girassol pode retardar a maturação } \\
\text { da barreira cutânea pós-natal em } \\
\text { RNPT. }\end{array}$ & $2 \mathrm{~B}$ \\
\hline $\begin{array}{l}\text { Effect of emollient therapy } \\
\text { on clinical outcomes } \\
\text { in preterm neonates in } \\
\text { Pakistan: a randomised } \\
\text { controlled triaß34 }\end{array}$ & $\begin{array}{l}\text { Arch. Dis. Child. } \\
\text { Fetal Neonatal } \\
\text { Ed. (2015) }\end{array}$ & $\begin{array}{l}258 \mathrm{RN} \\
\text { ECCR. }\end{array}$ & $\begin{array}{l}\text { Eficácia de aplicações } \\
\text { tópicas de óleo de coco } \\
\text { em RNPT. }\end{array}$ & $\begin{array}{l}\text { A terapia tópica emoliente foi eficaz } \\
\text { em manter a integridade da pele } \\
\text { e reduzir o risco de infecção da } \\
\text { corrente sanguínea em RNPT em } \\
\text { um hospital terciário no Paquistão. }\end{array}$ & $2 \mathrm{~B}$ \\
\hline $\begin{array}{l}\text { Topical Oil Application and } \\
\text { Trans-Epidermal Water } \\
\text { Loss in Preterm Very Low } \\
\text { Birth Weight Infants-A } \\
\text { Randomized Triaß }{ }^{\beta 5}\end{array}$ & $\begin{array}{l}\text { J. Trop. Pediatr } \\
\text { (2015) }\end{array}$ & $74 \mathrm{RN} ; \mathrm{ECCR}$. & $\begin{array}{l}\text { Aplicação tópica de óleo } \\
\text { de coco na perda de } \\
\text { água transepidérmica em } \\
\text { RNPT. }\end{array}$ & $\begin{array}{l}\text { A aplicação de óleo de coco reduziu } \\
\text { a PAT sem aumentar a colonização } \\
\text { cutânea em RN de muito baixo } \\
\text { peso. }\end{array}$ & $2 B$ \\
\hline $\begin{array}{l}\text { Topical Coconut Oil in } \\
\text { Very Preterm Infants: an } \\
\text { Open-Label Randomised } \\
\text { Controlled Trial}{ }^{\beta 6}\end{array}$ & $\begin{array}{l}\text { Neonatol. } \\
\text { (2017) }\end{array}$ & 72 RN; ECCR. & $\begin{array}{l}\text { Viabilidade, segurança } \\
\text { e os efeitos do óleo de } \\
\text { coco tópico na condição } \\
\text { da pele. }\end{array}$ & $\begin{array}{l}\text { O óleo de coco tópico manteve } \\
\text { melhor condição da pele em RNs } \\
\text { muito prematuros, sem efeitos } \\
\text { adversos. }\end{array}$ & $2 B$ \\
\hline $\begin{array}{l}\text { A randomized controlled } \\
\text { trial of } 1 \% \text { aqueous } \\
\text { chlorhexidine gluconate } \\
\text { compared with } 10 \% \\
\text { povidone-iodine for topical } \\
\text { antiseptic in neonates: } \\
\text { effects on blood culture } \\
\text { contamination rates }{ }^{37}\end{array}$ & $\begin{array}{l}\text { Infect. } \\
\text { Control Hosp. } \\
\text { Epidemiol. } \\
\text { (2013) }\end{array}$ & $\begin{array}{l}344 \text { RN; } \\
\text { ECCR }\end{array}$ & $\begin{array}{l}\text { Comparar antisséptico } \\
\text { tópico: clorexidina 1\% e } \\
\text { iodopovidona } 10 \% \text {. }\end{array}$ & $\begin{array}{l}\text { Um por cento de CHG foi mais } \\
\text { eficaz do que } 10 \% \text { de PI na redução } \\
\text { das taxas de contaminação da } \\
\text { cultura do sangue, e nenhuma } \\
\text { dermatite de contato foi observada. }\end{array}$ & $2 \mathrm{~B}$ \\
\hline $\begin{array}{l}2 \% \text { chlorhexidine-70\% } \\
\text { isopropyl alcohol versus } \\
\text { 10\% povidone-iodine for } \\
\text { insertion site cleaning } \\
\text { before central line insertion } \\
\text { in preterm infants: a } \\
\text { randomised tria }{ }^{\beta 8}\end{array}$ & $\begin{array}{l}\text { Arch. Dis. Child. } \\
\text { Fetal Neonatal } \\
\text { Ed. (2018) }\end{array}$ & $\begin{array}{l}304 \mathrm{RN} \\
\text { ECCR. }\end{array}$ & $\begin{array}{l}\text { Clorexidina 2\% em álcool } \\
\text { ou iodopovidona 10\% } \\
\text { em água, na prevenção } \\
\text { de infecção da corrente } \\
\text { sanguínea na assepsia } \\
\text { da pele pré inserção de } \\
\text { cateter. }\end{array}$ & $\begin{array}{l}\text { Não foi encontrada diferença } \\
\text { na taxa de infecção da corrente } \\
\text { sanguínea entre RNPTs tratados } \\
\text { com clorexidina 2\% em álcool e } \\
\text { iodopovidona 10\% em água e mais } \\
\text { lactentes tratados com iodopovidona } \\
\text { apresentaram disfunção tireoidiana. }\end{array}$ & $2 \mathrm{~B}$ \\
\hline $\begin{array}{l}0.2 \% \text { chlorhexidine } \\
\text { acetate as skin } \\
\text { disinfectant prevents } \\
\text { skin lesions in extremely } \\
\text { preterm infants: a } \\
\text { preliminary report } 39\end{array}$ & $\begin{array}{l}\text { Arch. Dis. Child. } \\
\text { Fetal Neonatal } \\
\text { Ed. (2018) }\end{array}$ & $\begin{array}{l}304 \mathrm{RN} ; \\
\text { Coorte re- } \\
\text { trospectivo. }\end{array}$ & $\begin{array}{l}\text { Lesões de pele e } \\
\text { infecção da corrente } \\
\text { sanguínea associada ao } \\
\text { cateter central em RNPT } \\
\text { extremo com gluconato } \\
\text { de clorexidina 0,5\% em } \\
\text { álcool } 70 \% \text { ou acetato de } \\
\text { clorexidina 0,2\%. }\end{array}$ & $\begin{array}{l}\text { O uso de acetato de clorexidina } \\
0,2 \% \text { como desinfetante da pele em } \\
\text { RNPT extremo resultou em redução } \\
\text { estatisticamente significativa das } \\
\text { lesões de pele, sem aumentar o } \\
\text { risco de infecção em comparação } \\
\text { com o gluconato de clorexidina } \\
\text { 0,5\% em álcool 70\%. }\end{array}$ & $2 B$ \\
\hline
\end{tabular}


Tabela 1. Continuação...

\begin{tabular}{|c|c|c|c|c|c|}
\hline $\begin{array}{c}\text { Título } \\
\text { (Referência) }\end{array}$ & $\begin{array}{c}\text { Periódico } \\
\text { (Ano) }\end{array}$ & $\begin{array}{l}\text { Amostra/ } \\
\text { Delineam. }\end{array}$ & Intervenção & Resultados & NE \\
\hline $\begin{array}{l}\text { Evaluation of efficacy } \\
\text { of skin cleansing with } \\
\text { chlorhexidine in prevention } \\
\text { of neonatal nosocomial } \\
\text { sepsis - a randomized } \\
\text { controlled tria }{ }^{40}\end{array}$ & $\begin{array}{l}\text { J. Matern. Fetal } \\
\text { Neonatal Med. } \\
\text { (2016) }\end{array}$ & $\begin{array}{c}140 \mathrm{RN} \\
\text { ECCR. }\end{array}$ & $\begin{array}{l}\text { Eficácia da limpeza da } \\
\text { pele com clorexidina } \\
\text { na prevenção da sepse } \\
\text { nosocomial. }\end{array}$ & $\begin{array}{l}\text { A limpeza da pele com clorexidina } \\
\text { diminui a incidência de sepse } \\
\text { por hemocultura e pode ser uma } \\
\text { intervenção fácil e barata para } \\
\text { reduzir a sepse neonatal em } \\
\text { países onde a taxa de mortalidade } \\
\text { neonatal é alta por causa da sepse. }\end{array}$ & $2 \mathrm{~B}$ \\
\hline $\begin{array}{l}\text { Effect of topical application } \\
\text { of chlorhexidine for } \\
\text { umbilical cord care } \\
\text { in comparison with } \\
\text { conventional dry cord care } \\
\text { on the risk of neonatal } \\
\text { sepsis: a randomized } \\
\text { controlled trial}{ }^{\mid 11}\end{array}$ & $\begin{array}{c}\text { J. Trop. Pediatr. } \\
\text { (2013) }\end{array}$ & $\begin{array}{l}140 \mathrm{RN} \\
\text { ECCR. }\end{array}$ & $\begin{array}{l}\text { Clorexidina no cordão } \\
\text { umbilical versus cuidado } \\
\text { seco para prevenir sepse. }\end{array}$ & $\begin{array}{l}\text { O uso da clorexidina no cuidado do } \\
\text { cordão umbilical previne a sepse } \\
\text { na UN. }\end{array}$ & $1 \mathrm{~B}$ \\
\hline $\begin{array}{l}\text { Impact of chlorhexidine } \\
\text { cleansing of the umbilical } \\
\text { cord on cord separation } \\
\text { time and neonatal } \\
\text { mortality in comparison to } \\
\text { dry cord care - a nursery- } \\
\text { based randomized } \\
\text { controlled trial}{ }^{42}\end{array}$ & $\begin{array}{l}\text { J. Matern. Fetal } \\
\text { Neonatal Med. } \\
\text { (2014) }\end{array}$ & $\begin{array}{l}140 \mathrm{RN} \\
\text { ECCR. }\end{array}$ & $\begin{array}{l}\text { Impacto da limpeza } \\
\text { do coto umbilical com } \\
\text { clorexidina versus } \\
\text { manutenção do coto } \\
\text { umbilical seco. }\end{array}$ & $\begin{array}{l}\text { O uso da clorexidina no cuidado do } \\
\text { coto umbilical encurta o tempo de } \\
\text { separação e diminui a mortalidade } \\
\text { neonatal na UN. Essa intervenção } \\
\text { pode ser usada para diminuir a } \\
\text { mortalidade neonatal. }\end{array}$ & $2 \mathrm{~B}$ \\
\hline $\begin{array}{l}\text { Two methods of cord care } \\
\text { in high-risk newborns: } \\
\text { their effects on hydration, } \\
\text { temperature, pH, and } \\
\text { floras of the cord area }{ }^{43}\end{array}$ & $\begin{array}{l}\text { J. Child Health } \\
\text { Care. } \\
\text { (2015) }\end{array}$ & 72 RN; ECCR. & $\begin{array}{l}\text { Água versus álcool na } \\
\text { hidratação, temperatura, } \\
\text { pH e flora bacteriana do } \\
\text { coto umbilical. }\end{array}$ & $\begin{array}{l}\text { O método de cuidado limpo e seco, } \\
\text { que usa água, pode ser suficiente } \\
\text { ou até melhor do que o álcool para } \\
\text { manter o ambiente fisiológico da } \\
\text { superfície do coto, com menos } \\
\text { chance de infecção em UN. }\end{array}$ & 2B \\
\hline $\begin{array}{l}\text { A comparison of nasal } \\
\text { trauma in preterm infants } \\
\text { extubated to either heated } \\
\text { humidified high-flow } \\
\text { nasal cannulae or nasal } \\
\text { continuous positive airway } \\
\text { pressure }\end{array}$ & $\begin{array}{l}\text { Eur. J. Pediatr. } \\
\text { (2014) }\end{array}$ & $\begin{array}{l}132 \mathrm{RN} \\
\text { ECCR. }\end{array}$ & $\begin{array}{l}\text { Verificar a incidência de } \\
\text { trauma nasal em RNPT } \\
\text { em CPAP ou sistema de } \\
\text { alto fluxo e avaliar o efeito } \\
\text { de dois protetores nasais. }\end{array}$ & $\begin{array}{l}\text { O sistema de alto fluxo resultou em } \\
\text { menos trauma nasal do que o CPAP } \\
\text { e foi mais significativo em RNs }<28 \\
\text { semanas de IG. O uso de curativos } \\
\text { protetores não diminuiu o trauma } \\
\text { nasal no RN em CPAP. }\end{array}$ & 2B \\
\hline $\begin{array}{l}\text { A comparative } \\
\text { effectiveness study of } \\
\text { continuous positive airway } \\
\text { pressure-related skin } \\
\text { breakdown when using } \\
\text { different nasal interfaces } \\
\text { in the extremely low birth } \\
\text { weight neonate }^{45}\end{array}$ & $\begin{array}{c}\text { Appl. Nurs. Res. } \\
\text { (2015) }\end{array}$ & 78 RN; ECCR. & $\begin{array}{l}\text { Diferenças na frequência, } \\
\text { gravidade de lesões } \\
\text { nasais e fatores de risco } \\
\text { associado ao uso de } \\
\text { diferentes interfaces } \\
\text { durante CPAP em } \\
\text { RN <1500 g: Pronga } \\
\text { nasal; máscara nasal; ou } \\
\text { máscara/pronga nasal } \\
\text { alternadas. }\end{array}$ & $\begin{array}{l}\text { Menos lesões foram detectadas } \\
\text { no grupo de interface alternadas. } \\
\text { Os preditores de lesão incluíram } \\
\text { número de dias no CPAP e média } \\
\text { atual da idade pós-natal. As melhores } \\
\text { práticas devem incluir a seleção } \\
\text { precisa do tamanho do dispositivo e } \\
\text { posicionamento do dispositivo CPAP } \\
\text { com avaliação focalizada da pele, } \\
\text { incluindo intervenção rápida para } \\
\text { lesão da pele. }\end{array}$ & $2 \mathrm{~B}$ \\
\hline $\begin{array}{l}\text { Peripherally inserted } \\
\text { central venous catheters: } \\
\text { frequency of complications in } \\
\text { premature newborn depends } \\
\text { on the insertion site }{ }^{46}\end{array}$ & $\begin{array}{l}\text { J. Perinatol. } \\
\text { (2014) }\end{array}$ & 62 RN; ECCR. & $\begin{array}{l}\text { Veia axilar na inserção } \\
\text { de cateter central } \\
\text { percutâneo: redução de } \\
\text { complicações. }\end{array}$ & $\begin{array}{l}\text { O uso da veia axilar como local de } \\
\text { inserção de uma linha do PICC se } \\
\text { correlacionou com complicações } \\
\text { significativamente menores do que em } \\
\text { outros locais de inserção em RNPT. }\end{array}$ & $2 \mathrm{~B}$ \\
\hline
\end{tabular}


Tabela 1. Continuação...

\begin{tabular}{|c|c|c|c|c|c|}
\hline $\begin{array}{c}\text { Título } \\
\text { (Referência) }\end{array}$ & $\begin{array}{c}\text { Periódico } \\
\text { (Ano) }\end{array}$ & $\begin{array}{l}\text { Amostra/ } \\
\text { Delineam. }\end{array}$ & Intervenção & Resultados & NE \\
\hline $\begin{array}{l}\text { Phototherapy rash } \\
\text { in newborn infants: } \\
\text { does it differ between } \\
\text { conventional and } \\
\text { light emitting diode } \\
\text { phototherapy? }\end{array}$ & $\begin{array}{l}\text { Pediatr. } \\
\text { Dermatol. } \\
\text { (2013) }\end{array}$ & 58 RN; ECCR. & $\begin{array}{l}\text { Incidência e extensão de } \\
\text { erupções cutâneas nos } \\
\text { diferentes dispositivos de } \\
\text { fototerapia. }\end{array}$ & $\begin{array}{l}\text { Os níveis de controle de bilirrubina } \\
\text { foram semelhantes para os dois } \\
\text { grupos. A frequência de erupções } \\
\text { cutâneas foi de } 36 \% \text { no grupo } \\
\text { fototerapia convencional (FC) e } \\
\text { 33\% no grupo fototerapia LED } \\
\text { (FL). As erupções cutâneas foram } \\
\text { máculas em 22,4\%, pápulas em } \\
\text { 8,6\% e erupções maculopapulares } \\
\text { em 3,4\% dos lactentes. Não houve } \\
\text { diferenças na incidência e extensão } \\
\text { das erupções cutâneas em RNPTs } \\
\text { que receberam FC ou FL. }\end{array}$ & $2 \mathrm{~B}$ \\
\hline $\begin{array}{l}\text { Effect of trunk-to-head } \\
\text { bathing on physiological } \\
\text { responses in newborns }\end{array}$ & $\begin{array}{l}\text { JOGN Nurs. } \\
\text { (2014) }\end{array}$ & $62 \mathrm{RN}$; ECCR. & $\begin{array}{l}\text { Efeito do banho (tronco } \\
\text { a cabeça) e (cabeça a } \\
\text { tronco) na estabilidade } \\
\text { do RN. }\end{array}$ & $\begin{array}{l}\text { RNs que foram banhados do tronco } \\
\text { à cabeça e cujas cabeças ficaram } \\
\text { molhadas por períodos mais curtos } \\
\text { se beneficiaram com recuperação } \\
\text { mais rápida da temperatura } \\
\text { corporal e diminuição da perda de } \\
\text { calor devido à evaporação. }\end{array}$ & $2 \mathrm{~B}$ \\
\hline $\begin{array}{l}\text { Comparing the effects of } \\
\text { swaddle and conventional } \\
\text { bathing methods on } \\
\text { behavioral responses in } \\
\text { preterm neonates }\end{array}$ & $\begin{array}{l}\text { Iran. J. } \\
\text { Neonatal. } \\
\text { (2016) }\end{array}$ & 50 RN; ECCR. & $\begin{array}{l}\text { Enrolamento e métodos } \\
\text { convencionais de } \\
\text { banho nas respostas } \\
\text { comportamentais. }\end{array}$ & $\begin{array}{l}\text { O enrolamento pode reduzir o } \\
\text { estresse neonatal durante o banho } \\
\text { e pode ser usado como um método } \\
\text { adequado e agradável para os } \\
\text { RNPT em UN. }\end{array}$ & $2 \mathrm{~B}$ \\
\hline $\begin{array}{l}\text { Diaper dermatitis care of } \\
\text { newborns human breast } \\
\text { milk or barrier cream }{ }^{50}\end{array}$ & $\begin{array}{l}\text { J. Clin. Nurs. } \\
\text { (2014) }\end{array}$ & 63 RN; ECCR. & $\begin{array}{l}\text { Leite materno ou creme } \\
\text { barreira para cicatrizar } \\
\text { dermatite das fraldas em } \\
\text { UN. }\end{array}$ & $\begin{array}{l}\text { c creme barreira oferece } \\
\text { resultados mais eficazes do que } \\
\text { o tratamento com leite materno } \\
\text { humano, particularmente no } \\
\text { tratamento de RN com dermatite } \\
\text { moderada a grave. }\end{array}$ & $2 B$ \\
\hline $\begin{array}{l}\text { Skin care product } \\
\text { evaluation in a group of } \\
\text { critically ill, premature } \\
\text { neonates: a descriptive } \\
\text { study }\end{array}$ & $\begin{array}{l}\text { J. Wound } \\
\text { Ostomy } \\
\text { Continence } \\
\text { Nurs. (2014) }\end{array}$ & $\begin{array}{c}29 \text { RN; } \\
\text { Descritivo. }\end{array}$ & $\begin{array}{l}\text { Produtos de cuidados } \\
\text { com a pele na condição } \\
\text { geral, eritema perineal } \\
\text { e dor. }\end{array}$ & $\begin{array}{l}\text { O uso de uma linha de produtos } \\
\text { de cuidados com a pele não } \\
\text { foi associado com aumentos } \\
\text { significativos na condição geral } \\
\text { da pele do RN medido com o } \\
\text { Neonatal Skin Condition Score, } \\
\text { eritema perineal medido com o Skin } \\
\text { Erythema Scale ou dor. }\end{array}$ & 4 \\
\hline
\end{tabular}

\section{DISCUSSÃO}

Os cuidados para prevenir lesões de pele em $\mathrm{RN}$ s encontrados nesta revisão foram divididos em sete categorias: termorregulação, uso de emolientes, antisséptico, dispositivos para oxigenação, acesso venoso, limpeza do coto umbilical e cuidados gerais.

\section{Termorregulação}

Nesta categoria foram incluídos 15 estudos que abordam a termorregulação do RN. A estabilidade térmica é um fator importante para o $\mathrm{RN}$ e requer atenção constante da equipe profissional que atua na assistência ao neonato. Segundo a Organização Mundial da Saúde (OMS), a faixa normal de temperatura corporal do $\mathrm{RN}$ está entre 36,5 e $37,5^{\circ} \mathrm{C}^{52}$. O risco maior de hipotermia ocorre nos primeiros minutos após o nascimento, fase em que o neonato se adapta ao ambiente extrauterino. Se medidas de proteção térmica não forem instauradas imediatamente, a temperatura central pode cair a uma taxa de 0,1 a $0,3{ }^{\circ} \mathrm{C}$ por minuto, comprometendo a estabilidade clínica do bebê ${ }^{19,53:}$ A hipotermia neonatal 
pode ocasionar estresse pelo frio e demandar maior gasto energético do $\mathrm{RN}$, aumentando consequentemente o risco de morbidade e mortalidade ${ }^{54}$. Cuidados para prevenir hipotermia ao nascimento são essenciais na assistência ao $\mathrm{RN}$, ainda na sala de parto. Ao analisar os dados desta revisão, percebe-se que esse aspecto gera inquietações nos pesquisadores, tendo em vista o número de estudos encontrados.

$\mathrm{O}$ contato pele a pele demonstrou diminuir a incidência de hipotermia no RN a termo ou RNPT tardio e nos bebês com peso maior ou igual a 1.800 gramas, quando iniciado nas primeiras horas após o nascimento e mantido, com mínima interrupção, durante as primeiras 24 horas de vida ${ }^{20}$. Há evidência que corrobora que o contato pele a pele, por pelo menos seis horas por dia, contribui com melhor ganho de peso e diminuição do tempo de internação hospitalar, além de ser uma prática de baixo custo e fácil realização ${ }^{55}$. Ao efeito termorregulador, somam-se os benefícios dessa prática para melhor desenvolvimento neurocomportamental e psicoativo, para aumento do vínculo entre a mãe e o bebê, estimulação sensorial adequada, diminuição da dor e do estresse do RNPT, entre outros ${ }^{56}$.

Diversos estudos indicam o uso de sacos de polietileno ou de vinil para envolver o RNPT logo após o nascimento 18,19,22,28. Em alguns momentos, essas práticas também foram associadas a outras medidas, a fim de identificar a melhor forma de alcançar e manter a termorregulação dos pacientes. Em RNPTs envolvidos em saco de polietileno do pescoço para baixo, o uso adicional de touca de polietileno vestida na cabeça ainda úmida, logo após o nascimento, foi associado com melhora significativa da média de temperatura ${ }^{27}$.

O RNPT apresenta massa muscular pouco desenvolvida e tecido subcutâneo escasso, diminuindo o isolamento térmico. As glândulas écrinas, células epiteliais responsáveis pelo suor, não são funcionais por ocasião da área corporal relativamente grande em relação ao peso desses bebês e à imaturidade fisiológica. Somado a essas questões, os RNs podem apresentar perda de calor através da evaporação, radiação, convecção e condução. A perda calórica por evaporação, que corresponde à PAT, é aproximadamente 10 vezes maior no RNPT do que nos bebês nascidos a termo ${ }^{57,58}$. Corroborando, o uso de envoltório plástico no corpo e na cabeça do RN minimizam as perdas de calor por evaporação e convecção ${ }^{59}$. Esse produto diminui o risco de hipotermia de 21 a $46 \%{ }^{60}$.

A eficácia da utilização de saco de polietileno também foi avaliada durante a realização de procedimentos. $\mathrm{O}$ uso de campo estéril de polietileno demonstrou melhorar a manutenção da temperatura retal, bem como prevenir hipotermia durante a inserção de cateter umbilical, quando comparado com o uso de campo fenestrado de tecido de algodão ${ }^{16}$.

Outras estratégias também foram testadas e vêm sendo recomendadas para contribuir com a estabilidade térmica e redução da hipotermia, tais como a colocação de uma folha de jornal entre dois lençóis de algodão pré-aquecidos ${ }^{29}$, o uso de manta térmica adicionada ao berço de calor radiante ${ }^{23}$, e a utilização de um colchão térmico condutor a partir de seis horas de vida ${ }^{26}$. Por outro lado, observou-se que o uso de um colchão termoestável associado ao uso de saco de polietileno no corpo, pode aumentar o risco de hipertermia na admissão na $\mathrm{UN}^{17}$.

Em uma revisão da Cochrane, foram encontrados 25 estudos que apresentam intervenções aplicadas até 10 minutos após o nascimento destinadas à prevenção de hipotermia em RNPT e/ou com baixo peso. Os autores revelaram a evidência de qualidade moderada para recomendar o uso de envoltórios ou sacos plásticos, principalmente em RNPTs com menos de 30 semanas de IG, pois essa prática melhorou a temperatura na admissão em UN ${ }^{61}$. Em contrapartida, as evidências são insuficientes para sugerir que essa prática reduza a mortalidade neonatal ou outras morbidades importantes. Os autores ressaltam ainda que, apesar de reduzirem o risco de hipotermia, o uso de colchões térmicos e a prática do contato pele a pele são baseados em pequenos estudos, não oferecendo evidências suficientes para apoiar recomendações oficiais. Segundo os autores, deve-se ter cuidado ao adotar métodos de aumento de temperatura de forma simultânea, a fim de evitar o superaquecimento do neonato ${ }^{61}$. A hipertermia estimula a liberação de neurotransmissores excitatórios no cérebro, ocasionando convulsão. Também piora a lesão cerebral de bebês asfixiados ${ }^{62}$.

Quanto ao peso ideal para transferir o $\mathrm{RN}$ da incubadora para o berço, foi demonstrado que bebês com 1.500 a 1.600 gramas, não apresentaram diferenças na regulação térmica, gasto energético ou ganho de peso ${ }^{25}$.Uma revisão da Cochrane realizada em 2011 fornece evidências de que RNs estáveis, com peso de 1.600 gramas, podem ser transferidos com segurança para um berço, sem que isso interfira na regulação térmica ou no ganho de peso. Reforça ainda que apresentam melhor estabilidade térmica, maior ganho de peso e menor tempo de internação ${ }^{63}$. 
Com base nos estudos encontrados sobre termorregulação, destaca-se que apenas a utilização de envoltórios e sacos plásticos imediatamente após o nascimento, bem como a transferência de RNs com peso a partir de 1.600 gramas da incubadora para o berço apresentam evidência robusta para apoiar a prática assistencial.

\section{Uso de emolientes}

Nesta categoria foram encontrados sete estudos que abordam o uso de emolientes na pele do RN. A pele é formada pela epiderme, derme e tecido subcutâneo. A camada mais externa da epiderme, o estrato córneo, exerce função de barreira epidérmica, impedindo a perda de fluidos através da pele e a invasão de agentes do meio externo ${ }^{64}$. A barreira epidérmica começa a se formar no feto com 24 semanas de gestação e o seu desenvolvimento histológico se completa com 34 semanas de gestação, mas funcionalmente ela contínua seu desenvolvimento durante o primeiro ano de vida do bebê $\hat{e}^{3,57,64,65}$. O RNPT apresenta função de barreira epidérmica comprometida, que o torna susceptível à PAT e infecção. $\mathrm{O}$ uso de emolientes parece melhorar a função de barreira epidérmica e protegê-lo desses riscos.

Em uma revisão sistemática da literatura com o objetivo de identificar estudos sobre a eficácia da terapia emoliente, foi concluído que o uso tópico desses produtos em RNPTs contribuiu significativamente para a redução da infecção hospitalar e da mortalidade neonatal, além de aumentar o ganho ponderal diário ${ }^{66}$.

Estudo sobre a avaliação do efeito do uso de emolientes à base de petrolato ou óleo de girassol sobre as condições da pele e sobre o risco de infecção em RNPTs, demonstrou que os emolientes mantêm a integridade da pele e contribuem para a prevenção de infecção. No entanto, para otimizar os benefícios desses produtos, os autores recomendam que seu uso seja iniciado imediatamente após o nascimento, quando a pele ainda se apresenta intacta ${ }^{30}$. Em contrapartida, foi observado que o uso do óleo de semente de girassol pode retardar a maturação da barreira cutânea em $\mathrm{RNPTs}^{33}$. Entretanto esse estudo foi realizado com uma amostra pequena de $\mathrm{RNs}$, sendo necessária a realização de mais estudos para sustentar esse achado.

A aplicação de óleo de coco duas vezes ao dia em RNPTs, desde o nascimento até completarem 28 dias de vida, foi eficaz no ganho de peso, manutenção da integridade da pele e redução do risco de infecção da corrente sanguínea ${ }^{34}$. $\mathrm{O}$ mesmo produto, quando aplicado em $\mathrm{RN}$ s com muito baixo peso, melhora a condição da pele, reduz a PAT e não aumenta a colonização cutânea ${ }^{35}$. Também foi observado que esse produto não causa nenhum efeito adverso no RNPT com menos de 30 semanas de $\mathrm{IG}^{36}$.

Ao analisar os estudos, observa-se que o uso de emolientes em RNPTs tem demostrado bons resultados no que concerne ao ganho de peso, manutenção da integridade da pele, prevenção de infecção e de dermatite atópica. Por outro lado, existe o risco de aumento da PAT e atraso na maturação da barreira epidérmica ${ }^{33}$. É importante salientar que o produto à base de petrolato testado não está disponível para uso no Brasil, entretanto os óleos de semente de girassol, mineral e de coco, são opções de baixo custo e facilmente encontrados no país.

Uma revisão da Cochrane avaliou a aplicação tópica de emolientes sobre a prevenção de infecção em RNPTs. Os autores identificaram 18 publicações, mas os dados não forneceram evidências de que infecção invasiva ou morte possam ser prevenidas pelo uso em $\mathrm{RNPTs}^{67}$. Segundo os autores, o uso de pomada emoliente em RNs com peso menor de 750 gramas pode aumentar o risco de infecção por estafilococos coagulase-negativo em países de alta renda. Já em países de baixa e média renda, embora exista alguma evidência de que o ganho ponderal possa ser incrementado pelo uso de óleo vegetal tópico, não há fortes evidências de que ele previna infecção ou diminua a mortalidade. Por isso, recomenda-se a realização de ECRs mais pragmáticos, a fim melhorar a qualidade da evidência para respaldar essa prática $^{67}$.

Resultados parciais de um estudo que está em desenvolvimento na China com uma amostra de 428 RNs vêm demonstrando que a terapia tópica com óleo de semente de girassol em RNs $<34$ semanas de IG antes de 72 horas de vida, quando comparada com o óleo mineral ou sem o uso de qualquer produto, demonstra-se superior e melhora a condição da pele do RNPT sem aumentar o risco de infecçãa ${ }^{68}$. Embora ainda não existam evidências de alta qualidade sobre o uso de emolientes em RNPTs, a Association of Womens's Health, Obstetric and Neonatal Nurses (AWHONN) recomenda a utilização, mas orienta atenção aos sinais de infecção sistêmica durante o uso desses produtos em RNs com peso inferior a 750 gramas $^{69}$.

\section{Antissépticos}

Nesta categoria foram encontrados quatro estudos que abordam o uso de antissépticos na pele do RN. 
Os RNs internados em UN estão susceptíveis às infecções relacionadas à assistência de saúde, assim, o uso de antissépticos tópicos antes da realização de procedimentos invasivos é fundamental para preveni-las ${ }^{70}$. Por outro lado, as alterações anatômicas e fisiológicas da pele do $\mathrm{RN}$, principalmente, do RNPT, colocam este paciente em risco de maior absorção de produtos tóxicos através da pele e de queimaduras químicas pelo uso dessas substâncias. Nesse sentido, a escolha do antisséptico torna-se um dilema para a equipe neonata ${ }^{69,70}$.

Os estudos incluídos nesta revisão demonstram que a identificação do produto ideal, que atue como asséptico sem causar efeitos adversos, é um tema relevante e ao mesmo tempo preocupante para os pesquisadores. $\mathrm{O}$ gluconato de clorexidina (GC) é um antisséptico de amplo espectro, sendo o agente de primeira escolha na preparação da pele antes da realização de procedimentos invasivos. Está disponível em soluções aquosas ou à base de álcool nas concentrações de $0,25,0,5,1,2$ e $4 \% 0^{70,71}$.

$\mathrm{O}$ uso de GC em solução aquosa a 1\% versus iodopovidona (PVPI) a 10\%, como antissépticos tópicos em RNs com peso maior ou igual 1.500 gramas, demonstrou que o GC é superior ao PVPI na redução das taxas de contaminação de hemocultura e que nenhuma reação na pele foi observada com o uso desses antissépticos $^{37}$. Um estudo multicêntrico realizado na Irlanda também não encontrou diferenças nas taxas de infecção da corrente sanguínea, bem como reações cutâneas, quando comparou o uso de GC a 2\% em solução alcoólica com a PVPI a 10\% em solução aquosa, na assepsia da pele de $\mathrm{RN}$ s com $\mathrm{IG}<31$ semanas. No entanto os autores relataram que $7,7 \%$ dos $\mathrm{RNs}$ alocados no grupo da PVPI apresentaram disfunção tireoidiana ${ }^{38}$. Esse achado é ratificado quando pesquisadores identificaram que a PVPI, devido a sua alta absorção através da pele, está associada ao risco elevado de hipotireoidismo transitório em RNPT, devendo ser utilizado com cautela e vigilância nessa população ${ }^{72}$.

Um estudo de coorte retrospectivo evidenciou redução estatisticamente significativa das lesões cutâneas em RNPTs menores de 30 semanas de IG com o uso de acetato de clorexidina a $0,2 \%$, sem aumentar o risco de infecção ${ }^{39}$. Reforça-se que as soluções alcoólicas de clorexidina estão mais associadas a reações adversas, como queimaduras e dermatite na pele dos bebês, com maior grau de gravidade em RNPTs e extremo baixo peso ${ }^{71}$.

No que se refere aos efeitos do banho com antisséptico na redução da incidência de sepse neonatal, o uso de clorexidina se mostrou eficaz. Os autores ressaltam que essa pode ser uma opção fácil e barata para os países que apresentam alta taxa de mortalidade neonatal por sepse ${ }^{40}$. Por outro lado, em uma revisão sistemática da Cochrane, os autores concluíram que a qualidade da evidência para apoiar a higienização da pele do RN com a clorexidina ao nascimento é baixa e que pode aumentar o risco de hipotermia ${ }^{73}$.

Os estudos sobre o uso de antissépticos demonstram que não há evidências de alta qualidade para indicar a escolha de um produto ideal, que atue de forma eficaz na assepsia ao mesmo tempo em que propicie segurança na prevenção de lesões de pele em RNs internados.

\section{Dispositivos para oxigenação}

Nesta categoria foram encontrados dois artigos que abordam cuidados com dispositivos de oxigenação.

O RN internado em UN necessita de vários dispositivos clínicos para assegurar sua sobrevivência. Em contrapartida, ao mesmo tempo em que contribuem para o cuidado, também colocam em risco a integridade cutânea do paciente. $\mathrm{O}$ uso de dispositivos pode ocasionar lesão por pressão, por fricção e por remoção de adesivo ${ }^{3}$. Em revisão da Cochrane, buscou-se comparar os efeitos de diferentes métodos de fixação do tubo endotraqueal em RNs. Os estudos apresentavam baixa qualidade metodológica e risco significativo de viés. A extubação acidental foi o resultado mais encontrado. Os autores concluíram que não há evidências para recomendar um método seguro e eficaz para fixar o tubo em $\mathrm{RNs}^{74}$.

Embora possam ocasionar lesão relacionada à retirada de adesivos, os dispositivos de cuidados críticos como tubos endotraqueais devem permanecer fortemente fixados. $\mathrm{O}$ uso de curativos de barreira cutânea em placa, entre a pele e o adesivo de fixação do tubo, pode descolar e causar extubação acidental, comprometendo a segurança do paciente. Por esse motivo, esses produtos bem como as fitas com baixa adesividade são contraindicados ${ }^{74-76}$.

Com relação à lesão por pressão, mais de $90 \% \mathrm{em}$ RNPTs estão relacionadas com o uso de dispositivos ${ }^{1}$. A partir dos estudos incluídos nesta revisão, percebe-se que a utilização de pressão positiva contínua das vias aéreas (CPAP, do inglês Continuous Positive Airway Pressure) pode favorecer a ocorrência dessas lesões. A incidência de lesão nasal demonstrou ser significativamente reduzida com o uso de cânula de alto fluxo em comparação com o CPAP, principalmente, em RNs menores de 28 semanas de IG. Entretanto, neste estudo, dois protetores cutâneos avaliados durante o uso dos dispositivos não foram associados à redução da lesão nasal no RN em CPAP44. 
Diferentes interfaces nasais foram comparadas durante $o$ uso de CPAP em RNs com peso menor de 1.500 gramas. Os pesquisadores identificaram eritema e lesão significativamente menores no grupo em que pronga nasal e máscara foram alternados a cada quatro horas. Os autores observaram ainda que o risco para lesão aumenta na medida em que o tempo de terapia se prolonga por mais de três dias. Ressaltam que o uso de barreiras cutâneas, fisioterapia respiratória, experiência clínica do enfermeiro e avaliação da pele são estratégias que devem ser consideradas na prevenção de lesão relacionada ao uso desse dispositivo ${ }^{45}$.

A utilização de uma barreira de pele (hidrocoloide) durante o tratamento com CPAP em RNPTs e baixo peso, demonstrou reduzir a incidência de lesão nasal. Os autores concluíram que essa estratégia pode ser efetiva na prevenção de lesão relacionada ao $\mathrm{CPAP}^{77}$. $\mathrm{O}$ uso de curativo sob os dispositivos propicia a formação de uma barreira cutânea entre a pele e o dispositivo, reduzindo a pressão e o cisalhamento ${ }^{78}$. Em contrapartida, outro estudo ${ }^{44}$ não demonstrou redução de lesões com uso de protetor cutâneo, no entanto não foi utilizado um grupo sem proteção nasal, o que pode indicar viés.

A partir dos estudos sobre oxigenação incluídos nesta revisão, observa-se que não há evidências de qualidade que sustentem um método adequado para fixação do tubo endotraqueal, mas é contraindicado o uso de barreira de proteção dado o risco de extubação. A alternância entre prongas e máscaras nasais e a utilização de barreira protetora entre a pele e o dispositivo são estratégias que podem contribuir para a prevenção de lesões relacionadas ao uso de CPAP.

\section{Acesso venoso}

Nesta categoria foi encontrado apenas um estudo que aborda o tema acesso venoso. $\mathrm{O}$ uso de medicamentos e soluções por via endovenosa são essenciais ao tratamento do RN internado, mas o expõe ao risco de lesões por infiltração e extravasamento. Essas lesões ocorrem pela administração inadvertida de medicamento ou fluido no tecido circundante ao invés do vaso sanguíneo, sendo secundárias ao deslocamento do cateter intravenoso ou à composição química de alguns medicamentos. Os medicamentos intravenosos irritantes e vesicantes, quando infundidos fora do vaso, ocasionam irritação da veia, dor e flebite química no local da injeção, podendo evoluir para lesão profunda. A infiltração somente será um verdadeiro extravasamento se o agente ofensor for vesicante. Entretanto ambos são destrutivos, causando lesão na frágil pele do $\mathrm{RN}^{79,80}$.

Pelas consequências que podem trazer ao $\mathrm{RN}$, essas lesões devem ser prevenidas e devem ser tomadas algumas medidas como priorizar cateteres de poliuretano com menor calibre para punções periféricas, pois são mais flexíveis, causam menor irritação da cânula na parede do vaso, reduzem o risco de flebite mecânica e de complicações infecciosas ${ }^{81}$; evitar punções em áreas de flexão, pois são de difícil fixação e podem ocasionar descolamento do curativo e deslocamento do cateter durante a mobilização, interferindo na manutenção do acesso venoso ${ }^{69,80}$; a estabilização do cateter deve ser realizada de forma asséptica, preferencialmente com membrana transparente semipermeável, permitindo monitoramento e avaliação constante do sítio de inserção e da área circunvizinha quanto sinais de infamação, infiltração e/ou extravasamento ${ }^{69,81}$.

As drogas irritantes $(\mathrm{pH}<5,0)$, vesicantes $(\mathrm{pH}>9,0)$ e as soluções com osmolaridade acima de $900 \mathrm{mOsm} / \mathrm{L}$ não devem ser infundidas em cateter venoso periférico, pois aumentam o risco para flebite química. A utilização de bomba eletrônica é essencial para controlar o fluxo de infusão de forma precisa. Esses equipamentos apresentam características de segurança como o alarme de oclusão e a proteção antifluxo livre, que alertam o profissional quanto aos possíveis problemas que possam comprometer o acesso venoso e a segurança do paciente ${ }^{80,81}$.

Os RNs apresentam maior dificuldade para punção venosa e maior fragilidade dos vasos, por esse motivo a troca rotineira do acesso venoso é contraindicada, recomenda-se que seja trocado somente quando clinicamente indicado ${ }^{82}$. O cateter venoso é um dispositivo invasivo e pode causar infecção da corrente sanguínea, por isso deve ser retirado quando a terapia intravenosa não for mais indicada ${ }^{80,81}$.

No que se refere ao uso de cateter central de inserção periférica (CIPP), a inserção desse dispositivo através da veia axilar em RNPTs acarretou em redução significativa de complicações como edema, inflamação, obstrução e infecção, quando comparados com outros locais de inserção $0^{46}$. Em contraponto, um estudo não incluído nesta revisão evidenciou que a inserção deste cateter em veias do couro cabeludo também é viável e não resulta em aumento de complicações $^{83}$. Uma revisão da Cochrane verificou que o uso de CIPP favorece a entrada de nutrientes no RN que recebe nutrição parenteral (NP). Além disso, o CIPP reduz a necessidade de punção venosa e consequentemente dor. Não 
foram encontradas evidências que sustentem o aumento dos riscos de eventos adversos pelo uso desse cateter ${ }^{84}$.

Com relação ao uso de curativos antimicrobianos em acessos venosos, uma revisão da Cochrane avaliou se seu uso é seguro e efetivo na redução de infecção relacionada a cateter venoso central em $\mathrm{RNs}^{85}$. $\mathrm{O}$ estudo demonstrou que curativo de clorexidina reduziu a colonização do cateter, mas acarretou em maior risco de desenvolvimento de dermatite em RNPTs. Curativo de alginato e prata não apresenta diferença significativa na taxa de infecção, mas as evidências são insuficientes para apoiar o uso de curativo de alginato e prata em $\mathrm{RNs}^{85}$.

Com base nos estudos sobre a utilização de acesso venoso incluídos nesta revisão, observa-se que as evidências suportam a troca do cateter periférico somente quando necessário e a preferência pelo uso de CIPP para infusão de NP ou outras soluções que exijam tratamento prolongado.Já quanto ao uso de curativos antimicrobianos na prevenção de infecção, faltam estudos de qualidade para indicar tal prática. Ressalta-se que os efeitos da utilização de produtos químicos na pele do RN ainda não estão bem esclarecidos, devendo ser utilizados com cautela, principalmente nos RNPTs, que apresentam função de barreira cutânea imatura.

\section{Limpeza do coto umbilical}

Nesta categoria foram encontrados três estudos que abordam o cuidado com o coto umbilical.

O cordão umbilical recém-cortado é um local de colonização bacteriana e pode causar infecção e morte do RN. Entretanto práticas de higiene, principalmente em locais onde as condições de higiene são precárias, contribuem potencialmente para prevenir esses riscos ${ }^{86}$.

Um estudo demonstrou que o uso tópico de clorexidina no cordão umbilical diminuiu o tempo para queda, bem como preveniu sepse em $\mathrm{RNPTs}^{41}$. Um ano mais tarde, ao analisarem novamente os dados do estudo, os autores observaram ainda que o uso tópico de clorexidina no coto umbilical contribui com a diminuição da mortalidade neonatal ${ }^{42}$.

A aplicação de álcool bem como a limpeza apenas com água não demonstraram diferença quanto à hidratação, temperatura, $\mathrm{pH}$ e flora bacteriana do coto umbilical. Entretanto a água propiciou redução do tempo para queda ${ }^{43}$ Em revisão sistemática da Cochrane, os autores concluíram que no ambiente hospitalar de países em desenvolvimento, há evidência moderada para sustentar o uso de clorexidina no cordão umbilical do $\mathrm{RN}$ na redução do risco de infecção, mas ainda há incertezas quanto ao seu efeito na mortalidade neonatal. Já nos países desenvolvidos não existem evidências de qualidade que indiquem esse benefício, por isso recomenda-se que o coto seja mantido limpo e seco ${ }^{73}$.

Com base nos estudos sobre os cuidados com o cordão umbilical incluídos nesta revisão, observa-se que nos países em desenvolvimento existe evidência moderada que suporta o uso de clorexidina para prevenir infecção, mas não existe recomendação sobre a concentração ou solução de diluição adequada a ser utilizada. Nos países desenvolvidos, recomenda-se manter o local limpo e seco. No Brasil, o Ministério da Saúde orienta a utilização de álcool etílico a 70\% ou solução de clorexidina alcoólica a 0,5\% para higienização do coto umbilical em $\mathrm{RN}$ a termo e solução de clorexidina aquosa em RNPT extremo, a fim de proteger contra infecção ${ }^{87}$.

\section{Cuidados gerais}

Foram encontrados cinco estudos que abordam cuidados gerais com o RN. Nesta categoria serão discutidos o banho, a utilização de produtos de cuidado com a pele, fototerapia e dermatite de fraldas, temas que foram pouco encontrados nesta revisão. Com relação ao banho, um estudo demonstrou que quando realizado no sentido do tronco à cabeça permitiu melhor e mais rápida recuperação da temperatura corporal. De acordo com os autores, esses achados devem-se ao menor período em que o RN permaneceu com a cabeça molhada, contribuindo com a redução de perda de calor por evaporação ${ }^{48}$.

O banho é um procedimento que pode não ser prazeroso para o neonato ${ }^{88}$. Banhos menos frequentes diminuem a necessidade de manuseio e as chances de estresse pelo frio, propiciam melhor estabilidade fisiológica e comportamental do RNPT ${ }^{69}$. Por outro lado, a técnica de envolver o RN em uma toalha macia e imergi-lo na banheira com água até a região abaixo dos ombros contribuiu para reduzir o estresse, quando comparado com o banho sob torneira ${ }^{49}$.

Ressalta-se que o banho enrolado é uma prática recomendada pelo Ministério da Saúde do Brasil a partir do Método Canguru, pois propicia estimulação suave e frequente aos receptores térmicos, táteis e proprioceptivos, oferecendo estímulos poderosos que podem concorrer com a dor e o estresse, reduzindo o risco de desequilíbrio fisiológico no $\mathrm{RN}^{56}$. Em contrapartida, banho de torneira pode acarretar 
em queimaduras por escaldamento em crianças pequenas, devido à dificuldade em controlar a temperatura da água, que pode se tornar rapidamente quente, bem como pela falta de habilidade motora para escapar da água quente ${ }^{89}$.

Ainda em relação à higiene e hidratação do $\mathrm{RN}$, foi encontrado um estudo sobre a aplicação de uma linha específica de produtos de cuidado com a pele, em RNPTs internados em uma UN, incluindo soluções de limpeza, hidratantes e creme de óxido de zinco. Os produtos não melhoraram significativamente a condição da pele, o eritema perineal ou a dor ${ }^{51}$.

$\mathrm{O}$ uso de produtos no RN deve ser realizado com cautela. A aplicação tópica de alguns detergentes e agentes químicos pode comprometer a barreira cutânea e favorecer o desenvolvimento de eczemas ou dermatite atópica. Diante disso, deve-se preservar a integridade da pele, prevenir toxicidade e evitar a exposição a agentes químicos nocivos ${ }^{90}$.

Quanto à fototerapia, apenas um estudo foi encontrado e demonstrou que as erupções cutâneas apresentadas durante o tratamento são máculas, pápulas e erupções maculopapulares. Os autores não encontraram diferenças na incidência ou extensão das erupções quando diferentes equipamentos de fototerapia foram utilizados ${ }^{47}$.

No que se refere à dermatite de fralda, o creme barreira composto por $40 \%$ de óxido de zinco com formulação de óleo de fígado de bacalhau, bem como o leite humano, demonstraram apresentar períodos semelhantes na melhora clínica da lesão de dermatite das fraldas de RNPTs e a termo internados em UN. Entretanto o creme barreira propiciou melhor escore de pele pós-lesão, evidenciando que o creme oferece resultados mais eficazes do que o leite materno humano no tratamento desta lesã $0^{50}$. Os produtos à base de óxido de zinco são os mais utilizados na prevenção de dermatite de fraldas. Eles não são absorvidos pela pele, repelem os fluídos e possuem propriedades adstringentes, antissépticas e antibacterianas ${ }^{91}$.

A prevenção é a chave para o cuidado da dermatite de fraldas. Deve-se aumentar a frequência da troca de fraldas, realizar limpeza delicada da área perineal, aplicar produto que forneça proteção de barreira e avaliar o local a fim de identificar riscos de lesão ${ }^{92}$.

Os estudos sobre cuidados gerais incluídos nesta revisão demonstram que o banho através do enrolamento é um procedimento que pode ser replicado com segurança, o banho sob a torneira causa estresse e pode causar queimadura, não há evidências que assegurem o uso de produtos de cuidados de higiene na pele do RNPT, não foram encontradas recomendações para cuidado durante a fototerapia e o uso de creme barreira à base de óxido de zinco é seguro, propicia proteção da pele e prevenção da dermatite da área de fraldas.

Nesta revisão, chama-se atenção às práticas que não foram encontradas durante a busca nas bases de dados, como uso de escalas preditivas de risco de lesão, gerenciamento da umidificação da incubadora, prevenção de lesão por pressão, fixação de dispositivos, uso de medicamentos endovenosos, administração de medicamento intramuscular, cateterismo umbilical, coleta de exames e prevenção de lesão relacionada a adesivos, demonstrando que essas são lacunas do conhecimento sobre o tema.

\section{CONCLUSÃO}

Este estudo identificou diferentes estratégias para respaldar os profissionais de saúde, principalmente a equipe de enfermagem, no cuidado com a pele do RN. Ressalta-se que a termorregulação foi o tema mais estudado, embora o uso de emolientes, antissépticos e cuidado com o coto umbilical também tenham se destacado. Isso demonstra que as práticas que contribuem para a manutenção da temperatura corporal do $\mathrm{RN}$, desde os primeiros minutos de vida, são fundamentais para que o mesmo alcance a homeostase, sendo uma preocupação constante dos profissionais que atuam no cuidado neonatal.

A literatura demonstrou que a prevenção de lesões de pele é um tema relevante e atual, por outro lado observa-se que existe escassez de evidências robustas que possam sustentar, com segurança, práticas de cuidados com o RN e que as evidências científicas encontradas são insuficientes para englobar o universo do tema.

Ressalta-se a necessidade de fomentar a realização de pesquisas clínicas relacionadas ao cuidado com a pele do RN no Brasil, considerando a importância do tema e a carência de evidências para respaldar as práticas.

A partir dos resultados obtidos nesta revisão, compreende-se que as práticas de cuidado com a pele do $\mathrm{RN}$ exigem bases científicas, fundamentais para aperfeiçoar e assegurar a assistência prestada pela equipe neonatal. A realização de ECR demanda tempo, comprometimento 
por parte dos pesquisadores e disponibilidade de recursos, devendo ser empreendida com rigor metodológico e de forma constante, abordando todas as questões intervenientes do tema.

\section{FINANCIAMENTO}

Esta pesquisa contou com apoio da Coordenação de Aperfeiçoamento de Pessoal de Nível Superior - Brasil (CAPES) - Código de Financiamento 001.

\section{CONTRIBUIÇÃO DOS AUTORES}

Conceptualização, Santos SV; Ramos FRS e Costa R; Metodologia, Santos SV; Ramos FRS; Costa R e Batalha LMC; Investigação, Santos SV; Ramos FRS e Costa R; Redação - Primeira versão, Santos SV; Redação - Revisão \& Edição, Santos SV; Ramos FRS; Costa R e Batalha LMC; Aquisição de Financiamento, Ramos FRS e Costa R; Recursos, Santos SV; Ramos FRS e Costa R; Supervisão, Ramos FRS; Costa R e Batalha LMC.

\section{REFERÊNCIAS}

1. Visscher MO, Taylor T. Pressure ulcer in the hospitalized neonate: rates and risk factors. Sci Rep. 2014;4(7429): 1-6. https://doi.org/10.1038/srep07429

2. Chaves ACF, Santos AP, Ataíde KMN, Cunha KJB. Care and maintenance of premature neonate skin integrity. J Nurs UFPE on line. 2019;13(2):378-84

3. Cousins Y. Wound care considerations in neonates. Nursing Stand. 2014;28(46):61-70. https://doi. org/10.7748/ns.28.46.61.e8402

4. Migoto MT, Souza SNDH, Rossetto EG. Lesões de pele em bebês internados em uma unidade neonatal: estudo observacional. Online Braz J Nur. 2013;12(2):377-92.

5. Faria TF, Kamada I. Skin injuries in newborns in neonatal intensive care. Enferm Glob. 2017;17(1):211-36. https:// doi.org/10.6018/eglobal.17.1.273671

6. Santos SV, Costa R. Treatment of skin lesions in newborn children: meeting the needs of nursing staff. Rev EsC Enferm USP. 2014;48(6):985-92. https://doi. org/10.1590/S0080-623420140000700004

7. Santos SV, Costa R. Prevention of newborn skin lesions: knowledge of the nursing team. Texto-Contexto Enferm. 2015:24(3):731-9. https://doi.org/10.1590/010407072015011230014

8. Rumbo-Prieto JM, Romero-Martín M, Bellido-Guerrero D, Arantón-Areosa L, Raña-Lama CD, Palomar-Llatas F. Evaluación de las evidencias y calidad de las guías de práctica clínica sobre deterioro de la integridad cutánea: úlceras y heridas crónicas. Anales Sis San Navarra 2016;39(3):405-15.

9. Mccune SK, Mulugeta YA. Regulatory science needs for neonates: a call for neonatal community collaboration and innovation. Front Pediatr. 2014;2(135):1-3. https:// doi.org/10.3389/fped.2014.00135

10. Coppini R, Simons SHP, Mugelli A, Allegaert K. Clinical research in neonates and infants: Challenges and perspectives. Pharmacol Res. 2016;108:80-7. https:// doi.org/10.1016/j.phrs.2016.04.025

11. Mendes KDS, Silveira RCCP, Galvão CM. Integrative literature review: a research method to incorporate evidence in health care and nursing. Texto-Contexto Enferm. 2008;17(4):758-64. https://doi.org/10.1590/ S0104-07072008000400018

12. Joanna Briggs Institute - JBI. Reviewers' manual [Internet]. 2014 [cited 2018 Nov 08]. Available from: https:// nursing.Isuhsc.edu/JBI/docs/ReviewersManuals/ Mixed-Methods.pdf

13. Moher D, Liberati A, Tetzlaff J, Altman DG. PRISMA Group. Preferred reporting items for systematic reviews and meta-analyses: The PRISMA statement. Plos Med. 2009;6(7):e1000097. https://doi.org/10.1371/journal. pmed.1000097

14. Phillips B, Ball C, Sackett D, Badenoch D, Straus S, Haynes $B$, et al. Oxford Centre for Evidence-based Medicine. Levels of evidence [Internet]. Oxford: CEBM; 2009 [cited 2017 Jul 02]. Available from: https://www.cebm. net/2009/06/oxford-centre-evidence-based-medicinelevels-evidence-march-2009/

15. Mathew B, Lakshminrusimha S, Sengupta S, Carrion V. Randomized controlled trial of vinyl bags versus thermal mattress to prevent hypothermia in extremely lowgestational-age infants. Am J Perinatol. 2013;30(4):31722. https://doi.org/10.1055/s-0032-1324700

16. Nuntnarumit P, Swatesutipun B, Udomsubpayakul U, Thanacharoenpipat P. A randomized controlled trial of plastic drape for prevention of hypothermia during umbilical catheterization. Am J Perinatol. 2013;30(10):83942. https://doi.org/10.1055/s-0033-1333670

17. 17. Mccarthy LK, Molloy EJ, Twomey AR, Murphy JFA, O'Donnell CPF. A randomized trial of exothermic mattresses for preterm newborns in polyethylene bags. Pediatrics. 2013;132(1):135-41. https://doi. org/10.1542/peds.2013-0279 
18. Leadford AE, Warren JB, Manasyan A, Chomba E, Salas $A A$, Schelonka $R$, et al. Plastic bags for prevention of hypothermia in preterm and low birth weight infants. Pediatrics. 2013;132(1):128-34. https://doi. org/10.1542/peds.2012-2030

19. Belsches, TC, Tilly AE, Miller TR, Kambeyanda RH, Leadford A, Manasyan A, et al. Randomized trial of plastic bags to prevent term neonatal hypothermia in a resource-poor setting. Pediatrics. 2013;132(3):656-61. https://doi.org/10.1542/peds.2013-0172

20. Nimbalkar SM, Patel VK, Patel DV, Nimbalkar AS, Sethi A, Phatak A. Effect of early skin-to-skin contact following normal delivery on incidence of hypothermia in neonates more than $1800 \mathrm{~g}$ : randomized control trial. J Perinatol. 2014;34(5):364-8. https://doi.org/10.1038/jp.2014.15

21. Çağlar S, Gözen D, Ince Z. Heat loss prevention (help) after birth in preterm infants using vinyl isolation bag or polyethylene wrap. JOGNN Nurs. 2014;43(2):216-23. https://doi.org/10.1111/1552-6909.12291

22. Doglioni N, Cavallin F, Mardegan V, Palatron S, Filippone $M$, Vecchiato $L$, et al. Total body polyethylene wraps for preventing hypothermia in preterm infants: a randomized trial. J Pediatr. 2014;165(2):261-6. https:// doi.org/10.1016/j.jpeds.2014.04.010

23. Hsu KH, Chiang MC, Lin SW, Lin JJ, Wang YC, Lien R. Thermal Blanket to Improve Thermoregulation in Preterm Infants: A Randomized Controlled Trial. Pediatr Crit Care Med. 2015;16(7):637-43. https://doi. org/10.1097/PCC.0000000000000447

24. Reilly MC, Vohra S, Rac VE, Dunn M, Ferrelli K, Kiss K, et al. Randomized trial of occlusive wrap for heat loss prevention in preterm infants. J Pediatr. 2015;166(2):2628. https://doi.org/10.1016/j.jpeds.2014.09.068

25. Berger I, Marom R, Mimouni F, Kopelovich R, Dollberg $S$. Weight at weaning of preterm infants from incubator to bassinet: a randomized clinical trial. Am J Perinatol. 2014;31(6):535-40. https://doi. org/10.1055/s-0033-1354563

26. Bhat SR, Meng NF, Kumar K, Nagesh KN, Kawale A, Bhutani VK. Keeping babies warm: a non-inferiority trial of a conductive thermal mattress. Arch Dis Child Fetal Neonatal. 2015;100(4):309-12. https://doi.org/10.1136/ archdischild-2014-306269

27. Shafie H, Zakaria SZS, Adli A, Shareena I, Rohana J. Polyethylene versus cotton cap as an adjunct to body wrap in preterm infants. Pediatr Int. 2017;59(7):776-80. https://doi.org/10.1111/ped.13285

28. Hu XJ, Wang L, Zheng R, LV T, Zhang Y, Cao Y, et al. Using polyethylene plastic bag to prevent moderate hypothermia during transport in very low birth weight infants: a randomized trial. J Perinatol. 2018;38(4):332-6. https://doi.org/10.1038/s41372-017-0028-0

29. Agrawal N, Das K, Patwal P, Pandita N, Gupta A. Wrapping newborn infants in cloth and newspaper after delivery led to higher temperatures on arrival at the neonatal intensive care unit. Acta Paediatr. 2018;107(8):1335-8. https://doi.org/10.1111/apa.14211

30. Darmstadt G, Ahmed S, Ahmed ASMN, Saha S. Mechanism for prevention of infection in preterm neonates by topical emollients: a randomized, controlled clinical trial. Pediatr Infect Dis J. 2014;33(11):1124-7. https://doi. org/10.1097/INF.0000000000000423

31. Horimukai K, Morita K, Narita M, Kondo M, Kitazawa $H$, Nozaki M. Application of moisturizer to neonates prevents development of atopic dermatitis. J Allergy Clin Immunol. 2014;134(4):824-30. https://doi. org/10.1016/j.jaci.2014.07.060

32. Erdemir A, Kahramaner Z, Yuksel Y, Cosar H, Turkoglu E, Sutcuoglu S, et al. The effect of topical ointment on neonatal sepsis in preterm infants. J Matern Fetal Neonatal Med. 2014;28(1):33-6. https://doi.org/10.310 9/14767058.2014.900037

33. Kanti V, Grande C, Stroux A, Bührer C, Blume-Peytavi U, Garcia Bartels N. Influence of sunflower seed oil on the skin barrier function of preterm infants: a randomized controlled trial. Dermatology. 2014;229(3):230-9. https://doi.org/10.1159/000363380

34. Salam RA, Darmstadt GL, Bhutta ZA. Effect of emollient therapy on clinical outcomes in preterm neonates in Pakistan: a randomised controlled trial. Arch Dis Child Fetal Neonatal. 2015;100(3):210-5. https://doi. org/10.1136/archdischild-2014-307157

35. Nangia S, Paul VK, Deorari AK, Sreenivas V, Agarwal R, Chawla D. Topical Oil Application and Trans-Epidermal Water Loss in Preterm Very Low Birth Weight Infants-A Randomized Trial. J Trop Pediatr. 2015;61(6):414-20. https://doi.org/10.1093/tropej/fmv049

36. Strunk T, Pupala S, Hibbert J, Doherty D, Patole S. Topical Coconut Oil in Very Preterm Infants: An Open-Label Randomised Controlled Trial. Neonatol. 2018;113(2):14651. https://doi.org/10.1159/000480538

37. Nuntnarumit $P$, Sangsuksawang N. A randomized controlled trial of $1 \%$ aqueous chlorhexidine gluconate compared with $10 \%$ povidone-iodine for topical antiseptic in neonates: effects on blood culture contamination rates. Infect Control Hosp Epidemiol. 2013;34(4):430-2. https://doi.org/10.1086/669863

38. Kieran EA, O'Sullivan A, Miletin J, Twomey AR, Knowles SJ, O'Donnell CPF. 2\% chlorhexidine-70\% isopropyl alcohol versus $10 \%$ povidone-iodine for insertion site cleaning before central line insertion in preterm infants: a randomised trial. Arch Dis Child Fetal Neonatal. 2018;103(2):101-6. https:/doi.org/10.1136/ archdischild-2016-312193

39. Janssen LMA, Tostmann A, Hopman J, Liem KD. 0.2\% chlorhexidine acetate as skin disinfectant prevents skin lesions in extremely preterm infants: a preliminary report. Arch dis child fetal neonatal ed. 2018;103(2):97-100. https://doi.org/10.1136/archdischild-2017-312694 
40. Gupta B, Vaswani ND, Sharma D, Chaudhary U, Lekhwani S. Evaluation of efficacy of skin cleansing with chlorhexidine in prevention of neonatal nosocomial sepsis - a randomized controlled trial. J Matern Fetal Neonatal Med. 2016;29(2):242-7. https://doi.org/10.31 $09 / 14767058.2014 .996126$

41. Gathwala G, Sharma D, Bhakhri BK. Effect of topical application of chlorhexidine for umbilical cord care in comparison with conventional dry cord care on the risk of neonatal sepsis: a randomized controlled trial. J Trop Pediatr. 2013;59(3):209-13. https://doi.org/10.1093/ tropej/fmt003

42. Sharma D, Gathwala G. Impact of chlorhexidine cleansing of the umbilical cord on cord separation time and neonatal mortality in comparison to dry cord care - a nursery-based randomized controlled trial. J Matern Fetal Neonatal Med. 2014;27(12):1262-5. https://doi.or g/10.3109/14767058.2013.854325

43. Ahn Y, Sohn M, Jun Y, Lee E, Lee S. Two methods of cord care in high-risk newborns: their effects on hydration, temperature, $\mathrm{pH}$, and floras of the cord area. J Child Health Care. 2015;19(1):118-29. https://doi. org/10.1177/1367493513503580

44. Collins CL, Barfield C, Horne RSC, Davis PG. A comparison of nasal trauma in preterm infants extubated to either heated humidified high-flow nasal cannulae or nasal continuous positive airway pressure. Eur J Pediatr. 2014;173(2):181-6. https://doi.org/10.1007/s00431013-2139-8

45. Newnam KM, McGrath JM, Salyer J, Estes T, Jallo N, Bass WT. A comparative effectiveness study of continuous positive airway pressure-related skin breakdown when using different nasal interfaces in the extremely low birth weight neonate. Appl Nurs Res. 2015;28(1):36-41. https://doi.org/10.1016/j.apnr.2014.05.005

46. Panagiotounakou P, Antonogeorgos G, Gounari E, Papadakis S, Labadaridis J, Gounaris AK. TI: Peripherally inserted central venous catheters: frequency of complications in premature newborn depends on the insertion site. J Perinatol. 2014;34(6):461-3. https://doi. org/10.1038/jp.2014.36

47. Surmeli-Onay O, Ayse Korkmaz A, Yigit S, Yurdakok M. Phototherapy rash in newborn infants: does it differ between conventional and light emitting diode phototherapy? Pediatr Dermatol. 2013;30(5):529-33. https://doi.org/10.1111/pde.12083

48. So HS, You MA, Mun JY, Hwang MJ, Kim HK, Pyeon SJ, et al. Effect of trunk-to-head bathing on physiological responses in newborns. J Obstetric Gynecologic Neonatal Nurs: JOGNN. 2014;43(6):742-51. https://doi. org/10.1111/1552-6909.12496

49. Paran M, Edraki M, Montaseri S, Razavi Nejad MA. Comparing the effects of swaddle and conventional bathing methods on behavioral responses in preterm neonates. Iran J Neonatol. 2016;7(4):35-40. https://doi. org/10.22038/ijn.2016.7778
50. Gozen D, Caglar S, Bayraktar S, Atici F. Diaper dermatitis care of newborns human breast milk or barrier cream. J Clin Nurs. 2014;23(3-4):515-23. https://doi.org/10.1111/ jocn.12047

51. Young DL, Chakravarthy D, Drower E, Reyna, R. Skin care product evaluation in a group of critically ill, premature neonates: a descriptive study. J Wound Ostomy Continence Nurs. 2014;41(6):519-27. https:// doi.org/10.1097/WON.0000000000000083

52. World Health Organization. Thermal protection of the newborn: A practical guide [Internet] 1997 [cited 2018 Dec 23]. Available from: https://www.who.int/maternal_ child_adolescent/documents/ws42097th/en/

53. Foster J, Psalia K, Kenner C. Maintaining the Heat on Neonatal Hypothermia in Developing Countries. Newborn Infants Nurs Rev. 2014;14(2):42-4. https://doi. org/10.1053/j.nainr.2014.03.004

54. Knobel RB. Thermal stability of the premature infant in neonatal intensive care. Newborn Infants Nurs Rev. 2014;14(2):72-6. https://doi.org/10.1053/j. nainr.2014.03.002

55. Kanodia P, Bora R, Gupta A. Kangaroo mother care-a cost effective and an alternate method to manage hypothermia in low birth weight babies for better clinical outcome. Value Health. 2016;19(7):A405. https://doi. org/10.1016/j.jval.2016.09.338

56. Brasil. Ministério da Saúde. Secretaria de Atenção à Saúde. Departamento de Ações Programáticas Estratégicas. Atenção humanizada ao Recém-Nascido: Método Canguru: manual técnico. 3 ed. Brasília: MS [Internet] 2017 [cited 2018 Dec 20] Available from: http://bvsms.saude.gov.br/bvs/publicacoes/atencao_ humanizada_metodo_canguru_manual_3ed.pdf

57. Ness MJ, Davis DMR, Carey WA. Neonatal skin care: a concise review. Int J Dermatol. 2013;52(1):14-22. https:// doi.org/10.1111/j.1365-4632.2012.05687.x

58. Knobel RB. Fetal and neonatal thermal physiology. Newborn Infants Nurs Rev. 2014;14(2):45-9. https://doi. org/10.1053/j.nainr.2014.03.003

59. Pinheiro JM, Furdon SA, Boynton S. Decreasing hypothermia during delivery room stabilization of preterm neonates. Pediatrics. 2014;133(1):218-26. https://doi.org/10.1542/peds.2013-1293

60. Oatley HK, Blencowe H, Lawn JE. The effect of coverings, including plastic bags and wraps, on mortality and morbidity in preterm and full-term neonates. J Perinatol. 2016;36 Suppl 1:83-9. https://doi.org/10.1038/ jp. 2016.35

61. Mccall EM, Alderdice F, Halliday HL, Vohra S, Johnston L. Interventions to prevent hypothermia at birth in preterm and/or low birth weight infants. Cochrane Database Syst Rev. 2018;2:CD004210. https://doi. org/10.1002/14651858.CD004210.pub5 
62. Brasil. Ministério da Saúde. Secretaria de Atenção à Saúde. Departamento de Ações Programáticas Estratégicas. Atenção à saúde do recém-nascido: guia para os profissionais de saúde. Cuidados com o recémnascido pré-termo. 4 (2 ed.) Brasília: MS. [Internet] 2014 [cited 2018 Dec 20] Available from: http://bvsms. saude.gov.br/bvs/publicacoes/atencao_saude_recem_ nascido_v4.pdf

63. New K, Flenady V, Davies MW. Transfer of preterm infants from incubator to open cot at lower versus higher body weight. Cochrane Database Syst Rev. 2011;9:CD004214. https://doi.org/10.1002/14651858.CD004214.pub4

64. Visscher MO, Adam R, Brink S, Odio M. Newborn infant skin: physiology, development, and care. Clin Dermatol. 2015;33(3):271-80. https://doi.org/10.1016/j. clindermatol.2014.12.003

65. King A, Balaji S, Keswani SG. Biology and Function of Fetal and Pediatric Skin. Facial Plast Surg Clin N Am. 2013;21(1):1-6. https://doi.org/10.1016\%2Fj. fsc. 2012.10 .001

66. Salam RA, Das JK, Darmstadt GL, Bhutta ZA. Emollient therapy for preterm newborn infants - evidence from the developing world. BMC Public Health. 2013;13Suppl 3:S31. https://doi.org/10.1186/1471-2458-13-S3-S31

67. Cleminson J, Mcguire W. Topical emollient for preventing infection in preterm infants. Cochrane Database Syst Rev. 2016;(1):CD001150. https://doi.org/10.1002/14651858. CD001150.pub3

68. Hu X, Zhang Y. Effect of topically applied sunflower seed oil in preterm infants. Pediatr Crit Care Med. 2014;15(4):144-5. https://doi.org/10.1097/01.pcc.0000449366.67893.84

69. Association of women's health, obstetric and neonatal nurses (AWHONN). Neonatal skin care: evidence-based clinical practical guideline. 3 ed. Washington: AWHONN. 2013.

70. Sathiyamurthy S, Banerjee J, Godambe SV. Antiseptic use in the neonatal intensive care unit - a dilemma in clinical practice: An evidence-based review. World J Clin Pediatr. 2016;5(2):159-71. https://doi.org/10.5409/ wjcp.v5.i2.159

71. Neri I, Ravaioli GM, Faldella G, Capretti MG, Arcuri S, Patrizi. Chlorhexidine-Induced Chemical Burns in Very Low Birth Weight Infants. J Pediatr. 2017;191:262-5. https://doi.org/10.1016/j.jpeds.2017.08.002

72. Pinsker JE, McBayne K, Edwards M, Jensen K, Crudo DF, Bauer AJ. Transient Hypothyroidism in Premature Infants After Short-term Topical Iodine Exposure: An Avoidable Risk? Pediatr Neonatol. 2013;54(2):128-31. https://doi. org/10.1016/j.pedneo.2012.10.005

73. Sinha A, Sazawal S, Pradhan A, Ramji S, Opiyo N. Chlorhexidine skin or cord care for prevention of mortality and infections in neonates. Cochrane Database Syst Rev. 2015;3:CD007835. https://doi.org/10.1002/14651858. CD007835.pub2
74. Lai M, Inglis GDT, Hose $K$, Jardine LA, Davies MW. Methods for securing endotracheal tubes in newborn infants. Cochrane Database Syst Rev. 2014;7:CD007805. https://doi.org/10.1002/14651858.CD007805.pub2

75. MurrayJS, Noonan C, QuigleyS, Curley MAQ. Medical devicerelated hospital-acquired pressure ulcers in children: an integrative review. J Pediatr Nurs. 2013;28(6):585-95. https://doi.org/10.1016/j.pedn.2013.05.004

76. Mcnichol L, Lund C, Rosen T, Gray M. Medical adhesives and patient safety: state of the science: consensus statements for the assessment, prevention, and treatment of adhesive-related skin injuries. J Wound Ostomy Continence Nurs. 2013;40(4):365-80. https:// doi.org/10.1097/WON.0b013e3182995516

77. Imbulana DI, Owen LS, Dawson JA, Davis PG, Manley BJ. The pronose study: a randomised controlled trial of a nasal barrier dressing to reduce injury in preterm infants receiving binasal non-invasive respiratory support. J Paediatr Child Health. 2018;54Suppl 1:82-3. https://doi. org/10.1111/jpc.13882_219

78. Flanagan KA. Noninvasive ventilation in premature neonates. Adv Neonatal Care. 2016;16(2):91-8. https:// doi.org/10.1097/ANC.0000000000000273

79. Beall, V. Hall B, Mulholland JT, Gephart SM. Neonatal Extravasation: an overview and algorithm for evidence-based treatment. Newborn Infant Nursing Reviews. 2013;13(4):18995. https://doi.org/10.1053/j.nainr.2013.09.001

80. Infusion Nurses Society. Infusion Therapy Standards of Practice. J Infus Nurs. [Internet] 2016 [cited 2018 Dec 29];39(1S):S1-156. Available at: http://ins.tizrapublisher. com/hai13r/

81. Brasil. Agência Nacional de Vigilância Sanitária - ANVISA. Medidas de Prevenção de Infecção Relacionada à Assistência à Saúde. Agência Nacional de Vigilância Sanitária, Brasília: Anvisa [Internet] 2017 [cited 2018 Dec 20]. Available from: http://portal.anvisa.gov.br/ documents/33852/3507912/Caderno+4+-+Medidas+d e+Prevenção+de+Infecção+Relacionada+à+Assistênci a+à+Saúde/a3f23dfb-2c54-4e64-881 c-fccf9220c373

82. Webster J, Osborne S, Rickard CM, New K. Clinicallyindicated replacement versus routine replacement of peripheralvenous catheters. Cochrane Database Syst Rev. 2015;8:CD007798. https://doi.org/10.1002/14651858. CD007798.pub4

83. Callejas A, Osiovich H, Ting JY. Use of peripherally inserted central catheters (PICC) via scalp veins in neonates. J Matern Fetal Neonatal Med. 2016;29(21):3434-8. https:// doi.org/10.3109/14767058.2016.1139567

84. Ainsworth S, Mcguire W. Percutaneous central venous catheters versus peripheral cannulae for delivery of parenteral nutrition in neonates. Cochrane Database Syst Rev. 2015;10:CD004219. https://doi. org/10.1002/14651858.CD004219.pub4 
85. Lai NM, Taylor JE, Tan K, Choo YM, Ahmad KA, Muhamad NA. Antimicrobial dressings for the prevention of catheter-related infections in newborn infants with central venous catheters. Cochrane Database Syst Rev. 2016;3:CD011082. https://doi.org/10.1002/14651858. CD011082.pub2

86. Coffey PS, Brown SC. Umbilical cord-care practices in low- and middle-income countries: a systematic review. BMC Pregnancy Childbirth. 2017;17(68):1-21. https:// doi.org/10.1186/s12884-017-1250-7

87. Brasil. Ministério da Saúde. Secretaria de Atenção à Saúde. Departamento de Ações Programáticas Estratégicas. Atenção à saúde do recém-nascido: guia para os profissionais de saúde. Cuidados gerais. 1 (2 ed.) Brasília: MS. [Internet] 2014 [cited 2018 Dec 20]. Available from: http://bvsms.saude.gov.br/bvs/ publicacoes/atencao_saude_recem_nascido_v1.pdf
88. Ruschel LM, Pedrini DB, Cunha MLC. Hipotermia e banho do recém-nascido nas primeiras horas de vida. Rev Gaúcha Enferm. 2018;39:e20170263. https://doi. org/10.1590/1983-1447.2018.20170263

89. Baggott K, Rabbitts A, Leahy NE, Bourke P, Yurt RW. Pediatric sink-bathing: a risk for scald burns. J Burn Care Res. 2013;34(6):639-643. https://doi.org/10.1097/ BCR.0b013e31827e5049

90. Kuller JM. Infant Skin Care Products: What Are the Issues? Adv Neonatal Care. 2016;16(S5):3-12. https:// doi.org/10.1097/ANC.0000000000000341

91. Esser M. Diaper Dermatitis: what do we do next? Adv Neonatal Care. 2016;16Suppl 5:21-5. https://doi. org/10.1097/ANC.0000000000000316

92. Stamatas GN, Tierney NK. Diaper dermatitis: Etiology, manifestations, prevention, and management. Pediatr Dermatol. 2014;31(1):1-7. https://doi.org/10.1111/ pde. 12245 